\title{
Relations between source parameters for large Persian earthquakes
}

\author{
Majid Nemati ${ }^{1, \star}$, Mohammad Tatar $^{2}$ \\ ${ }^{1}$ Shahid Bahonar University of Kerman, Department of Geology, Kerman, Iran \\ ${ }^{2}$ International Institute of Earthquake Engineering and Seismology, Tehran, Iran
}

Article history
Received September 18, 2014; accepted July 16, 2015.
Subject classification:
Relation, Earthquake, Magnitude, Rupture length, Displacement, Persia.

\section{ABSTRACT}

Empirical relationships for magnitude scales and fault parameters were produced using 436 Iranian intraplate earthquakes of recently regional databases since the continental events represent a large portion of total seismicity of Iran. The relations between different source parameters of the earthquakes were derived using input information which has usefully been provided from the databases after 1900. Suggested equations for magnitude scales relate the body-wave, surface-wave as well as local magnitude scales to scalar moment of the earthquakes. Also, dependence of source parameters as surface and subsurface rupture length and maximum surface displacement on the moment magnitude for some well documented earthquakes was investigated. For meeting this aim, ordinary linear regression procedures were employed for all relations. Our evaluations reveal a fair agreement between obtained relations and equations described in other worldwide and regional works in literature. The $\mathrm{M}_{0}-$ $\mathrm{m}_{\mathrm{b}}$ and $\mathrm{M}_{0}-\mathrm{M}_{\mathrm{S}}$ equations are correlated well to the worldwide relations. Also, both $\mathrm{M}_{0}-\mathrm{M}_{\mathrm{S}}$ and $\mathrm{M}_{0}-\mathrm{M}_{\mathrm{L}}$ relations have a good agreement with regional studies in Taiwan. The equations derived from this study mainly confirm the results of the global investigations about rupture length of historical and instrumental events. However, some relations like $\mathrm{M}_{\mathrm{W}}-\mathrm{M}_{\mathrm{N}}$ and $\mathrm{M}_{\mathrm{N}}-\mathrm{M}_{\mathrm{L}}$ which are remarkably unlike to available regional works (e.g., American and Canadian) were also found.

\section{Introduction}

Relationships between source parameters of large earthquakes in the world have broadly been understood [e.g., Fuller 1987, Stromeyer et al. 2004, Bormann et al. 2007, Krystek and Anton 2007, Grünthal et al. 2009, Ristau 2009, Deniz and Yucemen 2010, Bethmann et al. 2011, Das et al. 2011, Baruah et al. 2012, Das et al. 2012, Gasperini et al. 2012, Grünthal and Wahlström 2012, Gasperini et al. 2013a, Gasperini et al. 2013b]. Magnitude is globally considered as the most efficient, measurable and a simple parameter for calculating the size of an earthquake. For the first time in the history of seismology Richter [1935] defined local magnitude scale for earthquakes. Many researchers [e.g., Sonley and Atkinson 2005, Chen et al. 2007, Yenier et al. 2008, Karimiparidari et al. 2013, Zare et al. 2014] have produced specific empirical relationships which convert various reported magnitude scales to $M_{W}$ in some regions including Iranian territory. A significant reason for these conversions is that various seismological agencies report different magnitude scales for the earthquakes. Conversion of various magnitude scales to the main and authentic magnitude scale of $M_{W}$ for most of the seismological catalogues is necessary $\left(m_{b}, M_{S}, M_{L}\right.$ as well as $M_{N}\left(=\log _{10}(\right.$ Amplitude $/ 4 \pi)+1.166 \log _{10}($ Epicentral Distance) - 0.1; Nuttli [1973]). Because the $m_{b}$, $M_{S}, M_{L}$ and also $M_{N}$ scales are independently calculated using maximum amplitude of body wave, surface wave, and shear wave of an earthquake in appropriate specific frequency ranges, respectively. Therefore, they cannot represent all source process energy of an earthquake; because the frequencies at which the above mentioned scales are calculated do not cover the whole rupture process. Also, a reliable earthquake catalogue, which usually contains homogeneous magnitude estimations for all events, is highly desirable. Homogeneous catalogues are applied in many seismic studies such as seismic hazard assessment, ground-motion prediction, long-term seismic strain rate assessment and also nuclear activity verification [Yenier et al. 2008].

Moreover, Shoja-Taheri et al. [2007] have used a large amount of strong-motion data recorded by $\mathrm{Na}$ tional Strong Motion Network of Iran (BHRC) to develop relations for routine determination of $M_{L}$ and $M_{W}$ from digital horizontal components of the strongmotion records. Also, Shahvar et al. [2013] have presented a unified and homogeneous catalogue for the Iranian plateau $\left(M_{W} \geq 4.0\right)$, created by merging data from two local catalogues and seven international agencies. Since, this operation requires the conversion of different magnitudes used by single agencies to a common 
type. In this attempt to convert different magnitude scales to $M_{W}$, regression relations that take into account errors on both variables are used.

Also, global empirical relationships between the basic source parameters (e.g., length, width and slip of a coseismic fault) and the moment magnitude [Hanks and Kanamori 1979, Kanamori 1979] of the corresponding earthquake have essentially been calculated [e.g., Kanamori and Anderson 1975, Bonilla et al. 1984, Wesnousky 1986, Wells and Coppersmith 1994, Papazachos and Papazachou 2003, Smith and Stock 2004]. Relations between earthquake parameters (e.g., scalar moment, fault length, faulted area, fault slip) and the magnitude of the corresponding earthquake are important issues for practical purposes. These relations can estimate the magnitude of an earthquake when such parameters are roughly known by either geological or seismological investigations. Ambraseys and Jackson [1998] summarized surface faulting cases in historical and recent earthquakes in the eastern Mediterranean region and in the Middle East (including Iran). They also derived relationships between magnitude, rupture length, surface displacements and mechanism, using the above mentioned dataset. Such empirical relations are also significant for theoretical reasons because they can physically test whether the models of the seismic rupture are valid [e.g., Utsu and Seki 1954, Tocher 1958, Nuttli 1983a, Nuttli 1983b, Ambraseys 1988, Wang and Ou 1998, Smith and Stock 2000, Papazachos et al. 2004, Karakaisis et al. 2010].

\section{Data and error analysis}

The database used in this study was gathered from various seismic catalogues. We used catalogues of the International Seismological Center (ISC as a main structure), the International Institute of Earthquake Engineering and Seismology of Iran (IIEES), the Institute of Geophysics of the University of Tehran (IGUT), the Engdahl relocated catalogue for 1900-2014 and many early to recent researches which have been carried out in Iran for the earthquakes after 1974. Appendix 1 shows the earthquake database used in this study. These earthquakes have occurred in response to the Arabian-Touran plates convergence (Figure 1a).

The parameters of $M_{0}$ and $M_{W}$ are basically calculated by the Centroid Moment Tensor (CMT) solution of the Harvard University catalogue [2014]; the location, depth, $m_{b}$ and $M_{S}$ were adopted from the ISC catalogue [2014]; $M_{N}$ was adopted from the IGUT catalogue [2014] and also $M_{L}$ magnitudes of the events from the IIEES catalogue [2014]. SRL, SSRL and MSD, the surface rupture length, subsurface rupture length and maximum surface displacement for coseismic faults of the Persiaan earthquakes were adopted from well documented papers. This data was gathered from the sources introduced in the reference column in the table of Appendix 1 , according to the fact that ISC reported depths are usually good for general classification as many of them are fixed depth mainly at $15 \mathrm{~km}$. Several studies have shown that some of them could be wrong as much as several kilometers [e.g., Maggi et al. 2000].

Reported $M_{L}$ and $M_{N}$ for the earthquakes in Appendix 1 were adopted from IIEES and IGUT catalogues, respectively. Most of $M_{W}, M_{S}$ and $m_{b}$ as well as all of $M_{0}$ values were achieved from Harvard catalogue considering that the Global CMT catalogue adopts $M_{S}$ and $m_{b}$ values from the other reliable sources. $S R L$, $S S R L$ and MSD for the earthquakes were adopted from geological surveys accomplished and published mainly by Geological Survey of Iran (GSI) (Appendix 1).

Separating the earthquake data with respect to their seismotectonic provinces, neither provides statistically different results nor improves statistical significance for the magnitude relations [e.g., Wells and Coppersmith 1994]. The Iranian earthquakes have mainly intra-plate behaviors and also Persian seismotectonic provinces are roughly associated with the same characteristics; although, Zafarani and Soghrat [2012] and Shoja-Taheri et al. [2007] have emphasized on the partial difference between Zagros and Alborz-Central Iran. Since, number of the events in each area (diagram) decreases, dividing the study area with respect to the seismotectonic provinces makes the results uncertain. This is the main reason of merging the data of all Iranian provinces except that of Makran and north of Alborz regions. According to these facts, we only excluded data of the plate-margin earthquakes from the database. This separation was necessary because of the significant differences between the plate-margin and the mid-plate earthquakes of a same seismic moment. A large platemargin earthquake has bigger rupture length, rupture area, average fault displacement, smaller rupture width as well as smaller static stress drop in comparison to a mid-plate event. Plots of $m_{b}$ versus $M_{S}, m_{b}$ versus $M_{0}$, as well as $M_{S}$ versus $M_{0}$, for plate-margin earthquakes show greater amounts of scatter in comparison to midplate earthquakes [Nuttli 1983a].

Karimiparidari et al. [2013] disregarded all aftershock and foreshocks in their newly compiled catalogue based on the procedure described by Gardner and Knopoff [1974]. Accordingly, the aftershocks and foreshocks are therefore excluded from our database based on their origin times, relative location to the mainshock and also over than 1 magnitude unit difference with the mainshock magnitude. Considering longer durations of aftershocks and foreshocks for larger earthquakes, no 
(a)

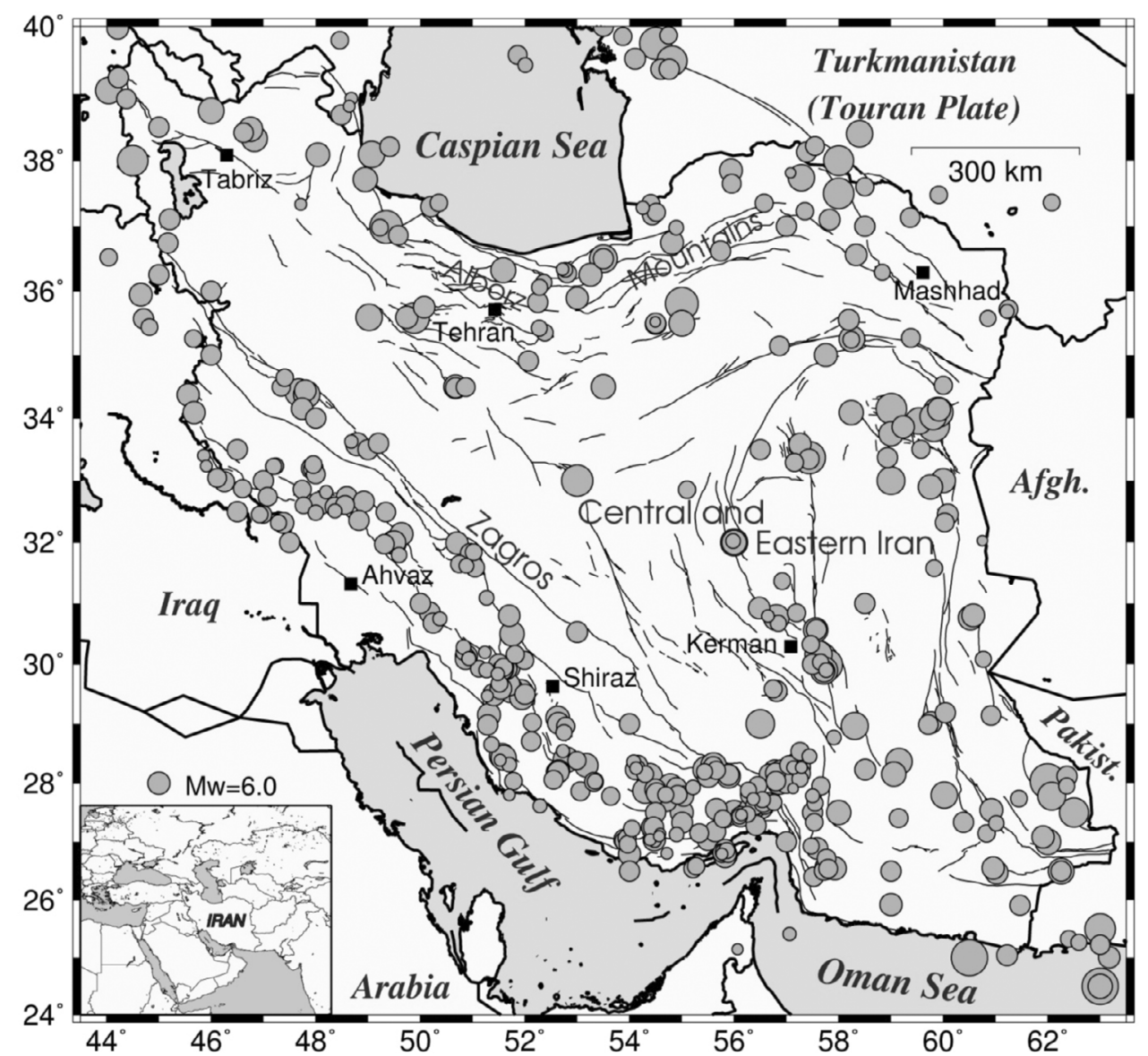

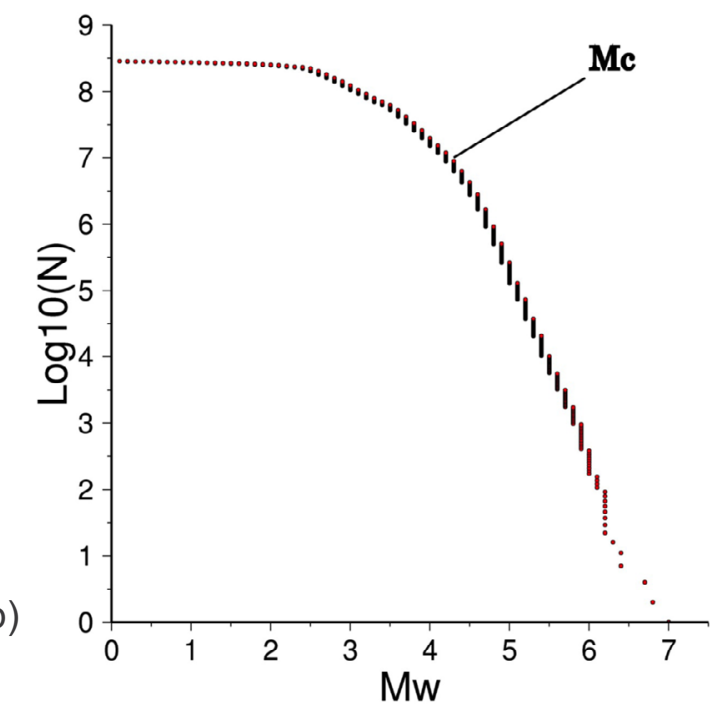

constant durations were considered for the aftershocks and foreshocks. Nemati [2014] has introduced equations for both the ISC and IGUT databases for spatially separating the aftershocks from the background seismicity in Iran. We also took advantage from Nemati [2014] relations $\left(\log _{10}(A)=0.45 M_{S}+0.23\right)$ as a general guide for separating the aftershocks which situate in an equivalent circular area of $A\left(\mathrm{~km}^{2}\right)$ centered by the mainshock location.

The basic need for any earthquake catalogue is homogeneity in the magnitude and also data complete-
Figure 1. (a) Fault map of Iran with the epicentral distribution of 436 earthquakes investigated in this study. Faults were adopted from the active fault map of Iran [Hessami et al. 2003]. (b) $M_{C}$ determination for our database.

ness. Concept of the completeness is that the data must include all earthquakes occur in a tectonical region during a specific time interval with magnitude larger than a certain value (magnitude of completeness $\left(M_{C}\right)$ ). Therefore assessment of $M_{C}$, usually estimated from bending of the Gutenberg-Richter diagram [Gutenberg and Richter 1956], is a significant issue. This is the smallest magnitude above which the catalogue is considered to be fully reported. In 1964-2014 period in ISC (after 1964), IIEES (after 2002) and IGUT (after 1996) catalogues (each reports seismic data with a global and regional seismological networks, respectively) this magnitude could optimistically be assumed to be 4.3 with a reliable and confident tolerance (Figure $1 \mathrm{~b}, M_{C}$ for ISC catalogue after 1964).

$m_{b}$ is obtained by using the waveform amplitude of the first $5 \mathrm{~s}$ of short period $\mathrm{P}$ waves recorded by short period sensors. $M_{S}$ is generally calculated from surface wave amplitudes with 20 s period. It can truly be used well for shallow earthquakes [Gutenberg and Richter 1956, Nuttli 1983a, Nuttli 1983b]. The original $M_{L}$ is based on recordings of a typical Wood Anderson (W-A) seismograph. If such recordings are not available, then 
we produce them by converting digital recordings of well calibrated sensors to synthetic W-A ones. Then $M_{L}$ is also determined from the peak amplitudes of the synthetic seismographs.

We examined the relationships between $M_{0}$ and $m_{b}, M_{S}$ and $M_{L}$ magnitude scales because $M_{W}$ could directly be calculated from $M_{0}$ for most of the earthquakes. $M_{W}$ could be easily obtained from the standard equation of $M_{W}=2 / 3\left(\log _{10}\left(M_{0}\right)-16.1\right)$ [IASPEI 2005]. Therefore, we calculated dependence of the magnitude scales with $M_{0}$. For pre-instrumental earthquakes $M_{S}$ was calculated from the maximum intensity $\left(I_{S}\right)$ by the formula $M_{S}=0.77 \mathrm{I}_{0}-0.07$ [Ambraseys and Melville 1982].

IGUT short period seismic stations are equipped with SS1 seismometers, medium-bands are equipped with Trillium-40s seismometers and broad-bands are equipped with CMG-3ESP-120s, CMG-3T-360s and also Trillium-240s seismometers. The IIEES seismometers are mainly broad-band of CMG-3T-360s type.

$M_{N}$ scale is basically introduced by Nuttli [1973] which defines the size of an earthquake by using the formula $M_{N}=\log _{10}(A / K T)+1.166 \log _{10}(R)-0.1$, where $A, K, T$ and $R$ are displacement amplitude (nm), amplification of the seismograph, natural period (s) of the seismograph and epicentral distance of the earthquake $(\mathrm{km})$, respectively. The magnitude of an earthquake released by IGUT is in the corrected Nuttli [1973] magnitude scale; $M_{N}=\log _{10}(A)+1.66 \log _{10}(R)-0.1$ for $R$ (epicentral distance) $\leq 106 \mathrm{~km}$ and $M_{N}=\log _{10}(A)+$ $2.5 \log _{10}(R)-1.8$ for $106 \mathrm{~km}<\mathrm{R} \leq 600 \mathrm{~km}$ and $A(\mathrm{~nm} / \mathrm{s})$ is maximum velocity amplitude for Iranian earthquakes recorded with velocity meters [Rezapour 2005].

Figure 1a displays the epicentral distribution of 436 earthquakes of Appendix 1 on the fault map of Iran. A unified magnitude is necessary for depiction of the epicenters in the map (Figure 1a) regarding that the earthquakes symbols are displayed with respect to their magnitudes. For unifying the magnitude scale of the earthquakes, we applied widely used and available relationships based on very wide data sets $\left(M_{W}=0.804 m_{b}\right.$ +1.25 and $M_{W}=0.74 M_{S}+1.81$ for $3.5<M_{S}<6.1$ and $M_{W}=0.83 M_{S}+1.25$ for $6.1<M_{S}<7.5$ [Scordilis 2006] for calculating $M_{W}$ for some earthquakes $\left(M_{W}(\right.$ Cal. $)$ column) in Appendix 1).

For evaluating the reliability of the equations, calculating a standard deviation as well as depicting a residual diagram for each equation is essential. Residual diagrams show how the difference between the calculated and observed dependent parameter versus the independent parameter, varies. If the fitted line to the residual plots closes to the horizontal state, the calculation is reliable [Yenier et al. 2008]. Deviation from horizontal slope for the fitted line dedicates uncertain- ties in the estimated parameter for an earthquake by our relation.

In this study, ordinary linear fit technique is used to compute the relationships between the magnitude scales and other source parameters. In the diagrams, symbols of some events may cover the others. All regressions for the diagrams were performed using the Origin software and map of Figure 1a and also all the diagrams were produced by GMT software [Wessel and Smith 1998].

\section{Seismic relations}

For the first time, Aki $[1966,1967]$ measured the value of seismic moment, $M_{0}$, for the 1964 Niigata Japanese earthquake and intelligently comprehended that the amplitude of a long period wave is proportional to $M_{0}$ of the corresponding earthquake.

The moment magnitude scale is roughly preferred by the majority of researchers for many applications, as it is more representative of the real size of an earthquake. We did not include scalar moments for pre-1976 events because only available $M_{0}$ with an independent method is appropriate for producing the relations. But, for post-1976 earthquakes the scalar moments of the Iranian earthquakes have appropriately been calculated with an independent method of Centriod Moment Tensor (CMT) solution by the Harvard University.

Large earthquakes ( $M>5.0$, cut-off magnitude) are the only target of this study. In other words, we excluded small earthquakes from processing because the global and regional databases could not record and therefore report all small earthquakes. Also, the smaller events may be covered by larger events in waveforms recorded with the worldwide global and regional seismological networks. Hence, small cut-off magnitude make the global and regional catalogues incomplete.

Linear fit suggests the equations according to the model of $Y=(A \pm a) X \pm(B \pm b)$, where: $Y$ and $X$ are dependent and independent parameters, respectively; $A$ and $B$ are linear coefficients; and also $a$ and $b$ are tolerance errors for $A$ and $B$, respectively (Table 1).

The error analysis was suggested evaluating the empirical relations obtained by the linear regression method and makes them satisfactory and reliable. A residual diagram presents the data scattering for each regression. Again, a linear trend was also fitted to each residual diagram determining whether the estimation is biased towards an independent parameter. Deviation from zero slope in this plot indicates biased estimation for the functional model. A dip less than 0.1 indicates a closer result to the average. In other words, a robust relation has a near zero slope for the fitted line to the corresponding residual diagram. Residuals for the dependent variables (e.g., $M_{0}, M_{W}, M_{N}$ and $S R L$ ) which 


\begin{tabular}{|c|c|c|c|c|c|c|}
\hline $\begin{array}{c}\text { Dependent } \\
\text { parameter }(Y)\end{array}$ & $\begin{array}{l}\text { Independent } \\
\text { parameter }(X)\end{array}$ & $\begin{array}{c}\text { Number } \\
\text { of } \\
\text { earth- } \\
\text { quakes }\end{array}$ & Relation $(Y=(A \pm a) X \pm(B \pm b))$ & $\begin{array}{l}\text { Standard } \\
\text { deviation }\end{array}$ & $\begin{array}{l}\text { Slop } \\
\text { for the } \\
\text { residual } \\
\text { diagram }\end{array}$ & Resemblance \\
\hline $\log _{10}\left(M_{0}\right)$ & $m_{b}$ & 150 & $\log _{10}\left(M_{0}\right)=(1.564 \pm 0.137) m_{b}+(16.128 \pm 0.759)$ & 0.540 & 1.374 & Nuttli [1983b] \\
\hline $\log _{10}\left(M_{0}\right)$ & $M_{S}$ & 137 & $\log _{10}\left(M_{0}\right)=(1.033 \pm 0.04) M_{S}+(19.044 \pm 0.254)$ & 0.327 & 0.081 & $\begin{array}{c}\text { Nuttli [1983b], } \\
\text { Chen et al. [2007] }\end{array}$ \\
\hline $\log _{10}\left(M_{0}\right)$ & $M_{L}$ & 44 & $\log _{10}\left(M_{0}\right)=(1.472 \pm 0.142) M_{L}+(16.195 \pm 0.803)$ & 0.356 & -0.133 & Chen et al. [2007] \\
\hline$M_{W}$ & $M_{N}$ & 45 & $M_{W}=(0.863 \pm 0.110) M_{N}+(0.818 \pm 0.615)$ & 0.308 & -0.030 & - \\
\hline$M_{N}$ & $M_{L}$ & 48 & $M_{N}=(0.915 \pm 0.074) M_{L}+(0.492 \pm 0.411)$ & 0.197 & -0.005 & $\begin{array}{l}\text { Karimiparidari } \\
\text { et al. [2013] }\end{array}$ \\
\hline $\log _{10}(M S D)$ & $M_{W}$ & 30 & $\log _{10}(M S D)=(0.491 \pm 0.238) M_{W}-(1.458 \pm 1.442)$ & 0.717 & 5.943 & - \\
\hline $\log _{10}(M S D)$ & $M_{W}$ & 22 & $\log _{10}(M S D)=(0.525 \pm 0.164) M_{W}-(1.701 \pm 1.084)$ & 0.361 & -3.388 & $\begin{array}{l}\text { Papazachos } \\
\text { et al. [2004] }\end{array}$ \\
\hline $\log _{10}(S R L)$ & $M_{W}$ & 22 & $\log _{10}(S R L)=(0.751 \pm 0.129) M_{W}-(3.586 \pm 0.841)$ & 0.296 & -0.008 & $\begin{array}{c}\text { Wells and } \\
\text { Coppersmith [1994] }\end{array}$ \\
\hline $\log _{10}(S S R L)$ & $M_{W}$ & 17 & $\log _{10}(S S R L)=(0.587 \pm 0.096) M_{W}-(2.291 \pm 0.634)$ & 0.183 & -0.012 & $\begin{array}{c}\text { Wells and } \\
\text { Coppersmith [1994] }\end{array}$ \\
\hline$S R L / S S R L$ & $M_{W}$ & 11 & $S R L / S S R L=(0.284 \pm 0.145) M_{W}-(1.166 \pm 0.960)$ & 0.241 & - & $\begin{array}{c}\text { Wells and } \\
\text { Coppersmith [1994] }\end{array}$ \\
\hline $\log _{10}(S R L)$ & $\log _{10}(S S R L)$ & 11 & $\log _{10}(S R L)=(0.1 .299 \pm 0.185) \log _{10}(S S R L)-(0.657 \pm 0.294)$ & 0.191 & - & - \\
\hline $\log _{10}(M S D)$ & $\log _{10}(S R L)$ & 26 & $\log _{10}(M S D)=(0.413 \pm 0.232) \log _{10}(S R L)+(1.333 \pm 0.321)$ & 0.614 & -0.003 & - \\
\hline
\end{tabular}

Table 1. Relationships and number of earthquakes used for each empirical equation.

contains differences between the observed and calculated (produced by our relation) variables were drawn versus their independent variables.

We compared Iranian relations obtained in this study with that of the global and regional equations like Taiwan, America and also Canada. Regarding to lack of the earthquake data (11 events) for $\log _{10}(S R L)$ $\log _{10}(S S R L)$ and $S R L / S S R L-M_{W}$ relations, the residual diagrams for both plots seems to be unnecessary.

\subsection{Scalar moment and magnitude}

For magnitude relations, some researchers separated the earthquakes with respect to their seismotectonic provinces (Karimiparidari et al. [2013] separated the data for $M_{S}-m_{b}$ relation for a wide range of magnitude), magnitudes (Nuttli [1983a, 1983b] for a wide range of magnitude), depths (Nuttli [1983a] for plate margin earthquakes) and mechanisms [Karakaisis et al. 2010]. We did not separate the earthquakes with respect to their seismotectonic provinces because separating the data according to extensional and compressional tectonic environments, neither provides statistically different results nor improves the statistical significance of the regressions [Wells and Coppersmith 1994]. We did not also separate the earthquakes with respect to their magnitudes and depths because the events situate in a relatively narrow magnitude (5.0-7.4) and depth (conti- nental events) ranges.

Regarding to the fact that $M_{W}$ directly depends on $M_{0}$ and is calculated from $M_{0}$, calculating either $M_{0}$ or $M_{W}$ values as the dependent parameter in the relations concludes the same results. The equations for magnitude scales were derived from specific magnitude ranges, considering that they meet the saturation values for each magnitude scale.

Chen et al. [2007] developed the seismic relations between four source parameters $\left(M_{0}, M_{S}, m_{b}\right.$ and $\left.M_{L}\right)$ using 201 Taiwan earthquakes during a 30 year period. They obtained results using the earthquakes with $m_{b}$ between 4.8 and 6.6. Surprisingly, their relations do not depart from Nuttli's [1983a] worldwide result. It is noticeable that neither Nuttli [1983a] nor Chen et al. [2007] separated their data with respect to the tectonical regimes.

\subsection{1. $\log _{10}\left(M_{0}\right)-m_{b}$}

Chen et al. [2007] has produced relations using 201 shallow earthquakes in Taiwan $\left(\log _{10}\left(M_{0}\right)=1.73 \mathrm{~m}_{b}+\right.$ 15.09 and also $M_{S}=1.46 m_{b}-2.52$ for $\left.4.8<m_{b}<6.6\right)$. For global mid-plate earthquakes, $M_{0}-M_{S}, M_{0}-m_{b}$ and $M_{S}-m_{b}$ relationships were inferred by Nuttli [1983a, 1983b] (e.g., $\log _{10}\left(M_{0}\right)=2.0 m_{b}+13.75 ; 4.5<m_{b}$ ). Scordilis [2006] also presented a global relation for $M_{0}-m_{b}\left(\log _{10}\left(M_{0}\right)=\right.$ $\left.1.20 m_{b}+17.90\right)$. In this study, we derived a relation be- 

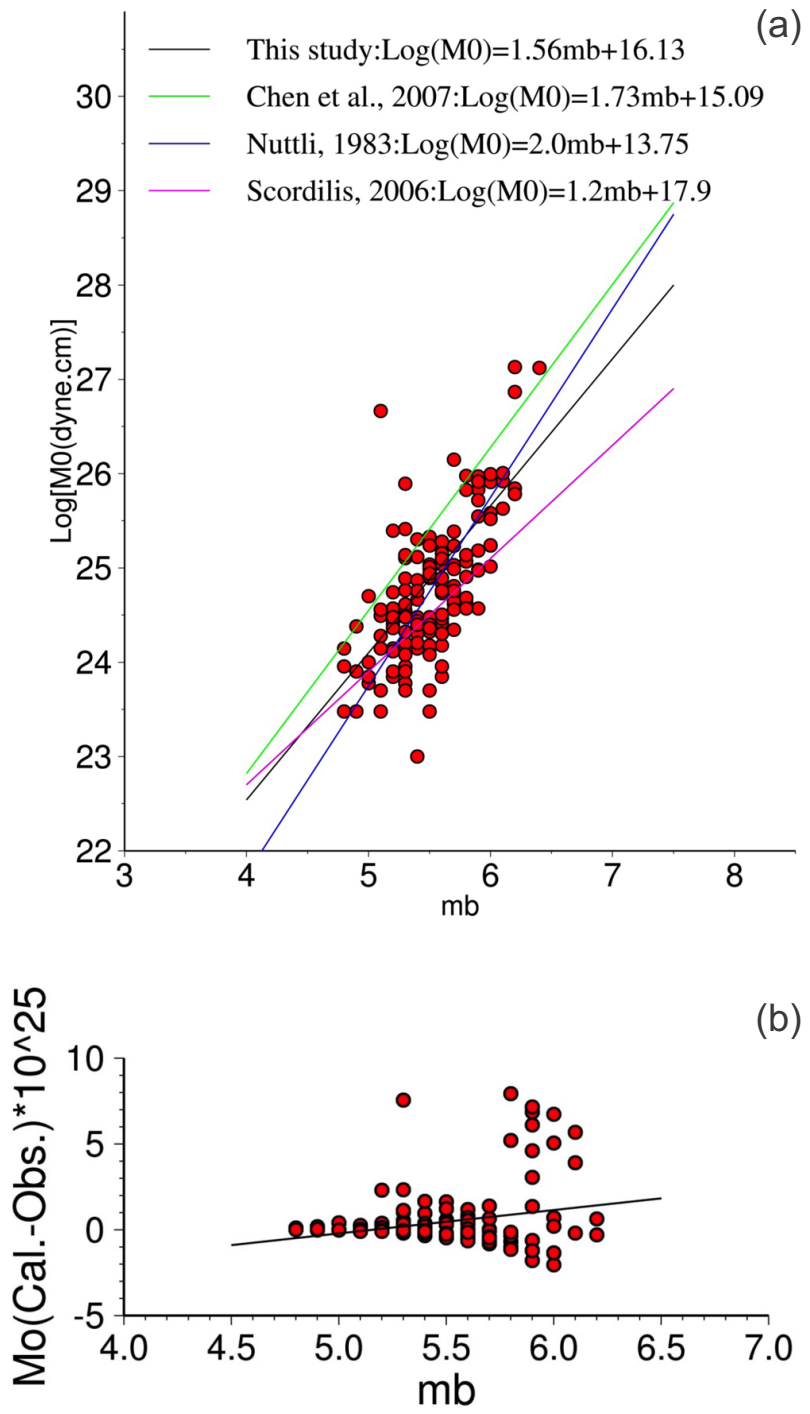

Figure 2. (a) $\log _{10}\left(M_{0}\right)$ versus $m_{b}$ and related regression line. The black line is for this study. Green and blue lines given by Chen et al. [2007] and Nuttli [1983], respectively. (b) Residual diagram for Figure 2a.

tween $\log _{10}\left(M_{0}\right)$ and $m_{b}$ using 150 continental earthquakes in Persian Plateau with $4.8<m_{b}<6.4$ (Figure 2a). Figure $2 \mathrm{~b}$ shows the $\log _{10}\left(M_{0}\right)$ residuals, which is the difference between the observed parameter from the Harvard catalogue and the calculated parameter in this study. This diagram dedicates to the deviation of the calculated $\log _{10}\left(M_{0}\right)$ from the observed values of the earthquakes with $m_{b}$ greater than 5.8. Therefore, the produced relation could not reliably be used for the earthquakes with this range of $m_{b}$. According to Figure $2 \mathrm{a}$ it is obvious that our achieved result $\left(\log _{10}\left(M_{0}\right)=\right.$ $\left.1.6 m_{b}+16.1\right)$ with a relatively high standard deviation (0.54) has more accordance with the Nuttli [1983a] worldwide equation than that of Chen et al. [2007] relation. Our results deviate from Scordilis [2006] in great magnitudes. The distribution deviates from linearity for big magnitude values in the residual diagram of Figure $2 \mathrm{~b}$ which is, basically due to $m_{b}$ saturation affects.

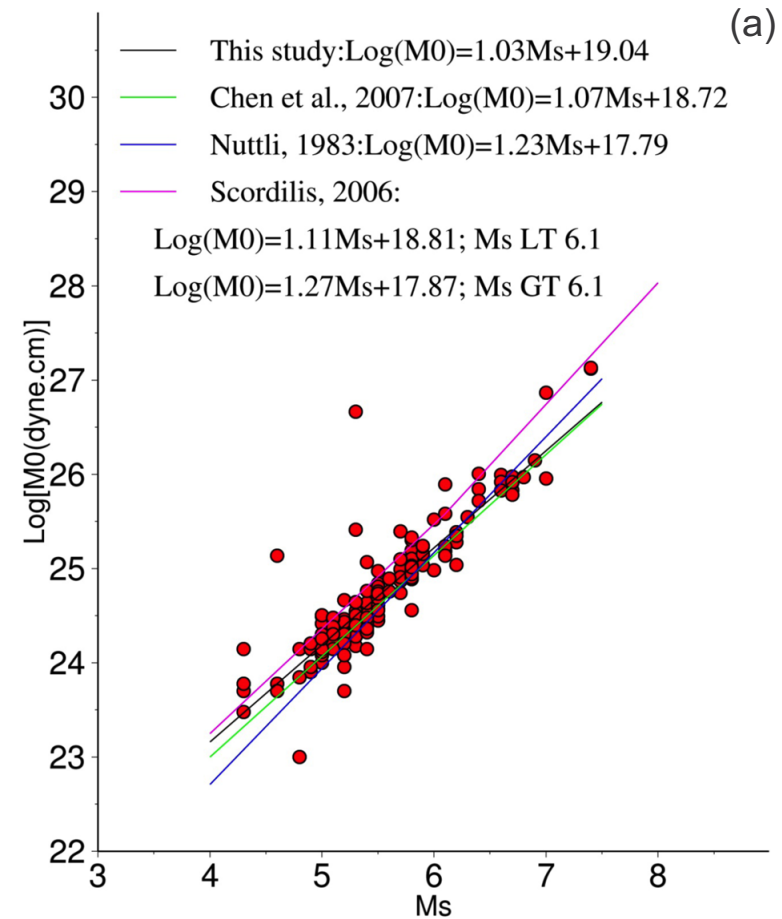

(a)

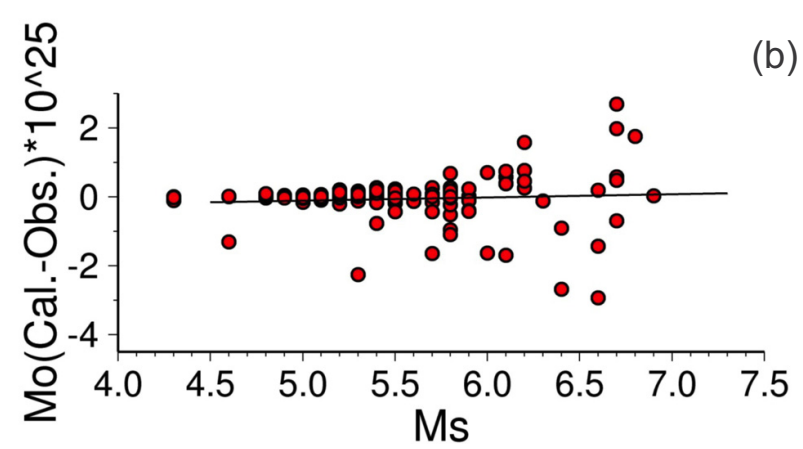

Figure 3. (a) $\log _{10}\left(M_{0}\right)$ versus $M_{S}$ for the mid-plate Iranian earthquakes. Equations for Scordilis [2006] were drawn for $M_{S}$ less than (LT) and greater than (GT) 6.1. The straight black line is for this study. (b) Residuals for scalar moment versus surface magnitude computed using ordinary linear regressions.

\subsection{2. $\log _{10}\left(M_{0}\right)-M_{S}$}

Chen et al. [2007] has also suggested a relation between $M_{0}$ and $M_{S}$ using 201 Taiwan earthquakes $\left(\log _{10}\left(M_{0}\right)=1.07 M_{S}+18.72 ; 4.1<M_{S}<7.9\right)$. For global mid-plate earthquakes, the $M_{0}-M_{S}$ relationship has also been inferred by Nuttli [1983a, 1983b] $\left(\log _{10}\left(M_{0}\right)=\right.$ $\left.1.23 M_{S}+17.79\right)$ as well as Scordilis [2006] $\left(\log _{10}\left(M_{0}\right)=\right.$ $\left.1.20 m_{b}+17.90\right)$. The source parameters for 137 Iranian earthquakes resulted a relation $\left(\log _{10}\left(M_{0}\right)-M_{S}\right.$, Figure 3a) with a linear regression and a standard deviation of 0.32 . The fitted line slope to the residuals (Figure $3 \mathrm{~b}$ ) for the $\log _{10}\left(M_{0}\right)$ is 0.081 . Notwithstanding that it is near zero value and also it is a good confirmation for the introduced relationship, scattering is still seen at the diagram for few greater events which indicates the magnitude saturation effects. The equation of this study for $M_{0}-M_{S}$ relation is correlated well to both Nuttli [1983a] 

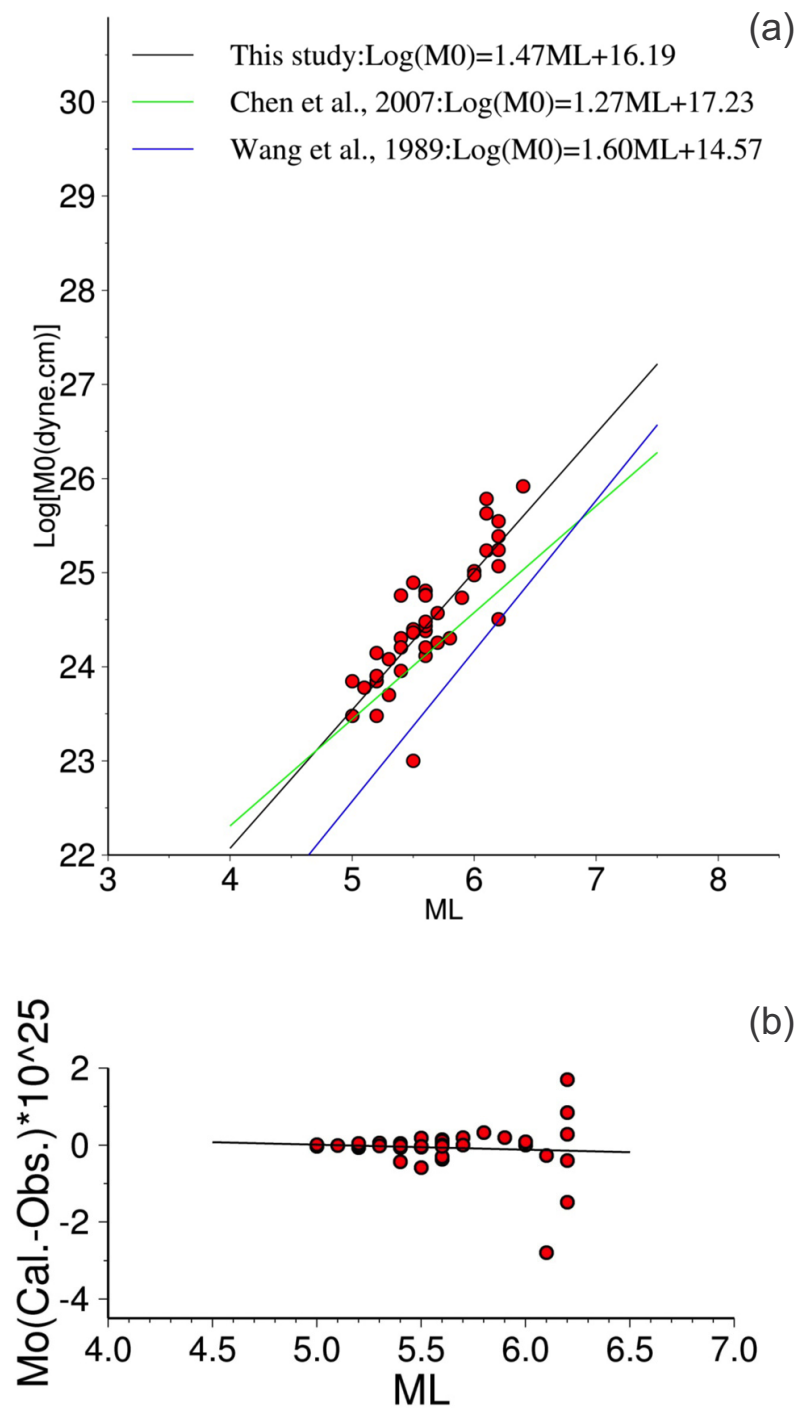

Figure 4. (a) Scatter plot of $\log _{10}\left(M_{0}\right)$ versus $M_{L}$. Lines are for comparisons of the conversion models with different studies in the literature. (b) Residual diagram for evaluating Figure 4a.

and Scordilis [2006] worldwide equations and also with Chen et al. [2007] regional relationship (blue, green and pink fitted lines in Figure 3a, respectively).

\subsection{3. $\log _{10}\left(M_{0}\right)-M_{L}$}

From previous works in the literature for $M_{0}-M_{L}$ relation we can point to both Chen et al. [2007] and Wang et al. [1989] works which have suggested relations for earthquakes in Taiwan. Using 44 Persian earthquakes with local magnitude, the plots of $\log _{10}\left(M_{0}\right)$ versus $M_{L}$, is depicted in Figure 4a. As Figure 4a shows a linear relationship with a standard deviation of 0.35 between the two parameters. This equation is reliably applicable to the earthquakes with $M_{L}$ magnitude less than 6.1 (Figure $4 \mathrm{~b}$ ). This limitation is arisen from $M_{L}$ saturation in big magnitude values. Although, there is correlation between the results of this study (black line in Figure 4a) for $M_{L}$ with that of Chen et al. [2007]

b)

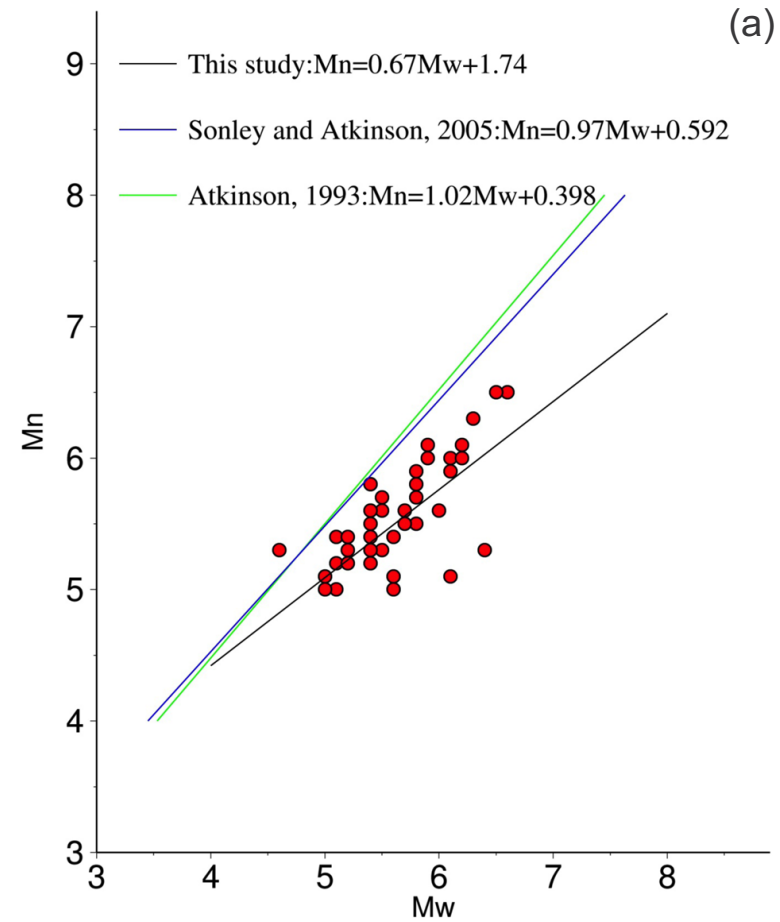

(a)

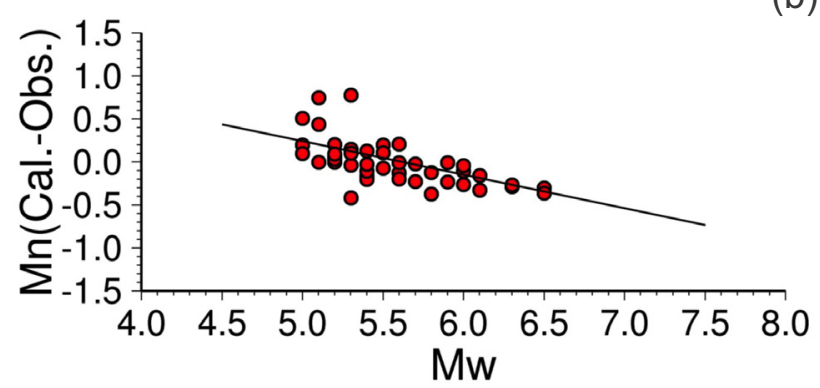

Figure 5. (a) Empirical relationship between $M_{W}$ and $M_{N}$ in Iran. Atkinson [1993] and Sonley and Atkinson [2005] equations correspond to the green and blue lines, respectively. Equation of the black line gives the regression result for this study. The two mentioned relationships (the American and Canadian) are very similar to each other. There is a vastly different magnitude range in the Iranian data. (b) Difference between the calculated and observed $M_{W}$ versus $M_{N}$ for the Iranian earthquakes.

(green line) at least for smaller magnitude events; it departs from Wang et al. [1989] relationship (blue line).

\subsection{Magnitude relations}

\subsection{1. $M_{N}-M_{W}$}

$M_{N}$ magnitude scale is the most common catalogue magnitude for the eastern North America, which has been introduced by Nuttli [1973]. $M_{N}$ magnitude is calculated using either the amplitude of the shear wave or Lg phase which is a multiply reflected and refracted shear wave.

Magnitudes of 45 Iranian earthquakes in $M_{N}$ and $M_{W}$ scales resulted in an equation (with standard devi- 
ation of 0.2 ) which calculates magnitudes in Nuttli scale for events with moment magnitude between 4.5 and 6.7.

For the Canadian earthquakes, Atkinson [1993] and Sonley and Atkinson [2005] have suggested equations compared with the relation of this study (Figure 5a). The result of this study is not correlated well with both relations. Although, all regions (America, Canada and Iran) are characterized by continental behaviors, a possible explanation for this difference is smaller areas of Canadian and American studied regions in comparison to the broader Iranian area covered by the earthquakes. The difference between the calculated and observed $M_{N}$ for the earthquakes applied in this section has been plotted as $M_{N}$ residuals, which is characterized with the slope of -0.3 (Figure $5 b$ ).

\subsection{2. $M_{N}-M_{L}$}

We could not find a relation for $M_{N}$ and $M_{L}$ in Iran except Karimiparidari et al. [2013] equation. But there are many relationships between $M_{L}$ and $M_{N}$ and the other magnitude scales in the literature. Chen et al. [2007] have produced relations using 125 earthquakes in Taiwan between $m_{b}$ and $M_{S}$ scales with $M_{L}\left(M_{S}=1.03 M_{L}-\right.$ -0.53 and $m_{b}=0.66 M_{L}+1.69$ both for $\left.4.7<M_{L}<7.2\right)$. Three relations between $m_{b}$ and $M_{L}$ which have also been determined are $m_{b}=0.85 M_{L}+0.27$ [Shin 1986]; $M_{L}=1.27 m_{b}-0.6$ [Wang et al. 1989], and $M_{L}=0.75 m_{b}+$ +1.94 [Cheng and Yeh 1989].

Using 48 large events in Iran we have calculated a reasonable equation between $M_{N}$ and $M_{L}$ with a standard deviation less than 0.2 (Figure 6a). $48 M_{L}$ values [IIEES 2013] (independent variable) have not been converted from the other scales rather calculated based on simulated records. IIEES seismological network records the waveforms with Broad-Band instruments. A credibility test performed for this relation to see if the conversion is near reality. Likely to the other relations, a test plot depicted for the residuals for $M_{N}$ scale with a fitted line to the events with a slope of -0.005 . Near zero slope for the fitted line to the residuals shows a reliable transformation for the magnitudes in the range of $4.9<M_{L}<6.2$ (Figure 6b). Our result for $M_{N}-M_{L}$ relation gives slightly greater values to $M_{N}$ in comparison to the Karimiparidari et al. [2013] equation for Iranian earthquakes.

\subsection{Coseismic rupture parameters and magnitude}

Karakaisis et al. [2010] calibrated relations globally between the magnitude of earthquakes and surface rupture length, surface displacement and rupture width for the earthquakes occurred in 464 BC to 1911 and 1911 to 2008 separately with the magnitude of completeness of 6.5 and 5.2, respectively. Murotani et al.
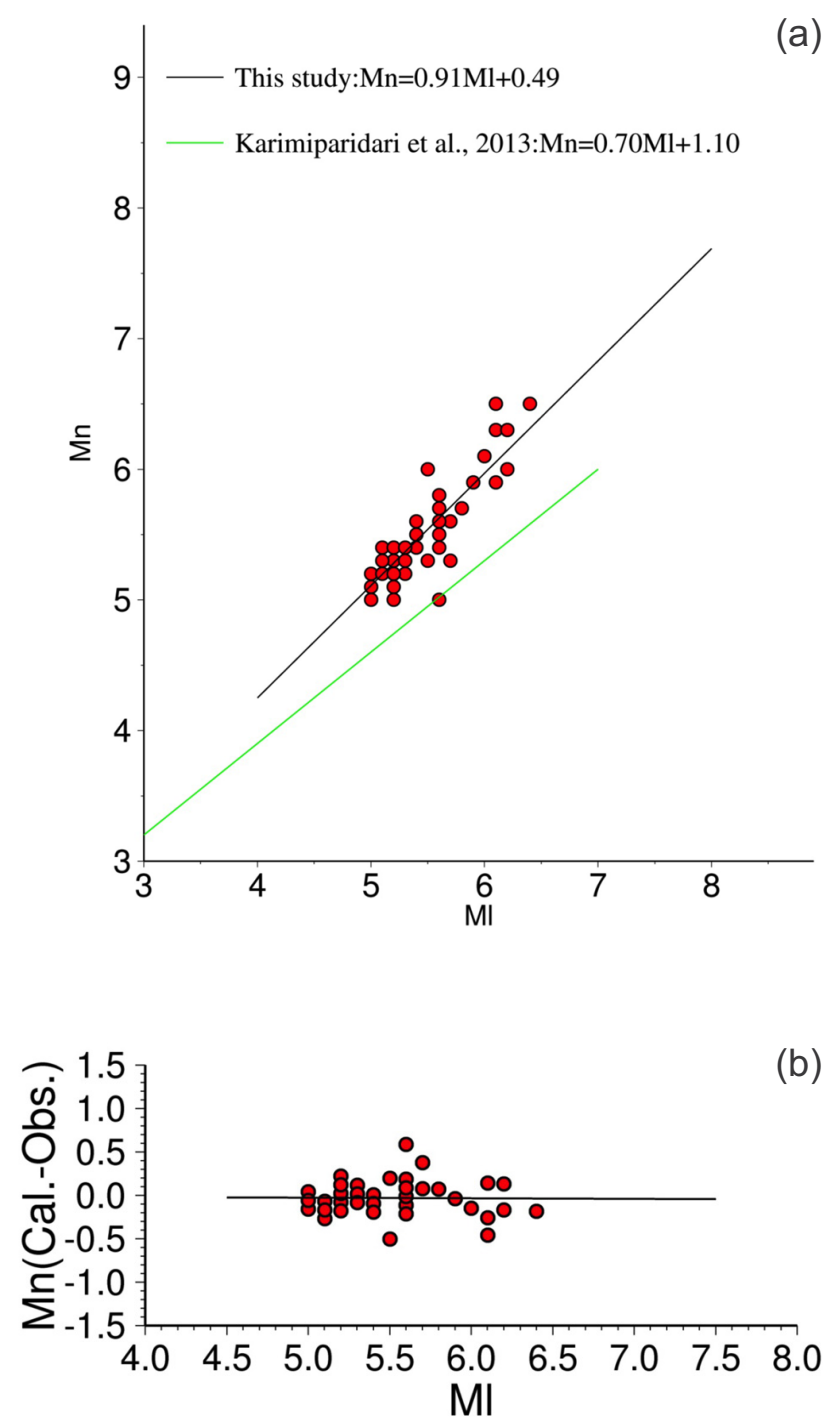

Figure 6. (a) $M_{N}-M_{L}$ relation for 48 Persian earthquakes (red dots); (b) credibility test for this diagram.

[2013] also derived relations between $M_{W}$, average slip and rupture area for great plate margin earthquakes around the world. Papazachos et al. [2004] have also related fault parameters to $M_{W}$ using 149 intraplate and plate-margin earthquakes.

Papazachos et al. [2004] have used a considerable number of published global earthquake data, which is homogeneous and fairly accurate to relate the fault length $(L, \mathrm{~km})$ and the fault width $(W, \mathrm{~km})$ as well as the average slip of a fault $(u, \mathrm{~cm})$, with $M_{W}$ for three kinds of faults (dip-slip and strike slip faults in continental regime and dip-slip faults in subduction regions). Papazachos et al. [2004] also obtained a relation between $M_{W}$ and average displacement $(D)$. They calculated average displacement from $M_{0}=\mu A D$ formula. Parameters $A$ and $\mu$ are ruptured area and the rigidity, respectively, and $M_{0}$ is calculated from $\log _{10}\left(M_{0}\right)=1.5 M_{W}+16.1$. Also, they obtained dependence between $A$ and $M_{W}$ from empirical diagrams. Here, we compared our results with Papazachos et al. [2004] relation for conti- 

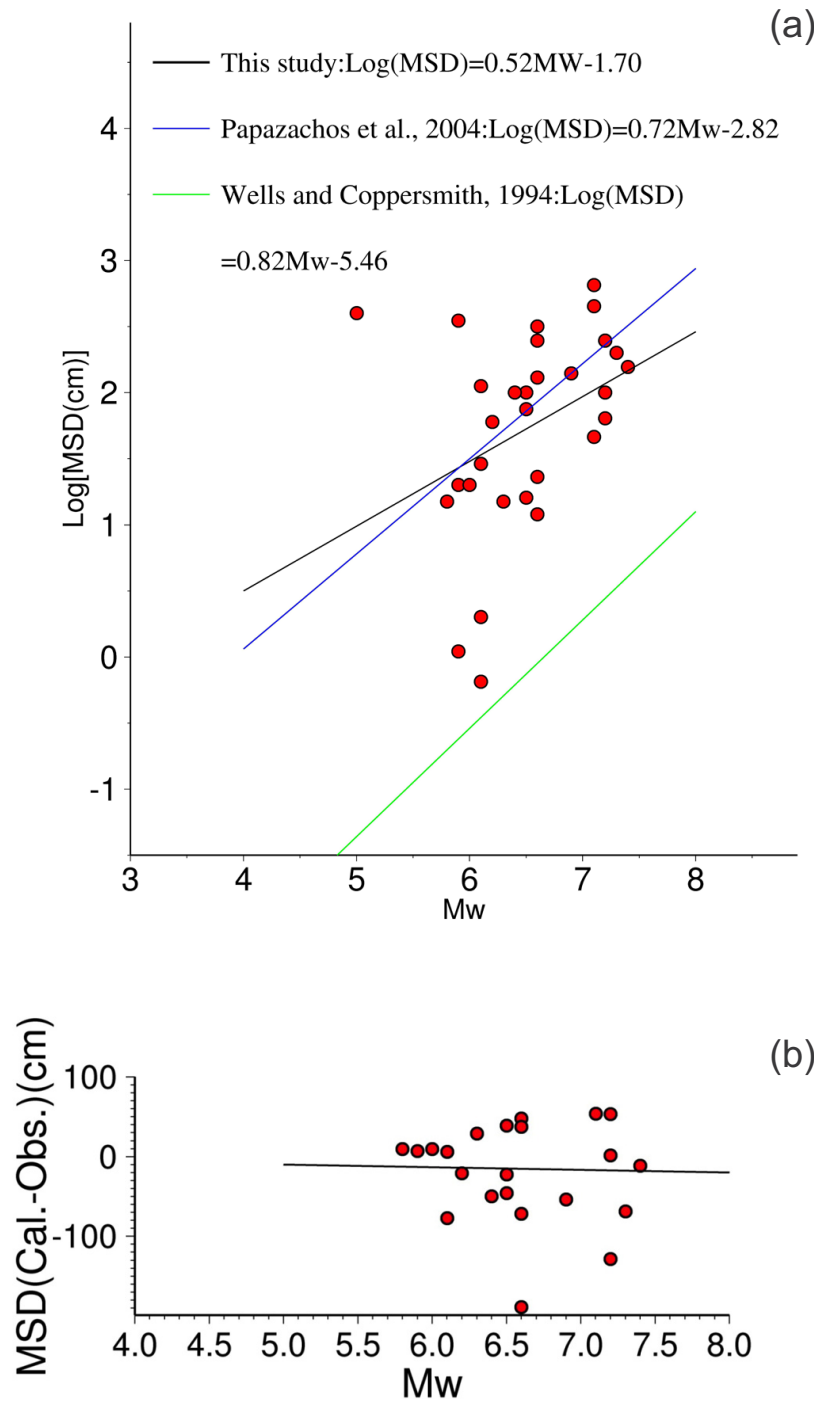

Figure 7. (a) Relation between coseismic fault displacement and $M_{W}$ for 30 mid-plate earthquakes in Iran; (b) reliability test for this diagram using 22 events.

nental faults. Papazachos et al. [2004] attended to global relations between seismic fault parameters and moment magnitudes for 193 continental earthquakes $(M>6.0)$.

$S R L, S S R L$ and MSD for Persian earthquakes in the next sections have been adopted from the field measurements, mainly performed by the Geological Survey of Iran (see Appendix 1 for the references).

\subsection{1. $\log _{10}(M S D)-M_{W}$}

We consider the resultant of maximum horizontal and vertical displacements of the earthquakes as maximum surface displacement (MSD). Using 30 Persian earthquakes with $M_{W}$ between 5.0 and 7.4, an equation was derived with a high value of standard deviation (0.7). The earthquakes with unusual surface ruptures, like 1972 Mishan-Zagros $\left(m_{b} 5.4\right.$ and $400 \mathrm{~cm}$ displacement; Berberian [1976a]), 1976 ChalderanAzarbaijan $\left(m_{b} 6.1\right.$ and $350 \mathrm{~cm}$ displacement; Berberian [1976a]), 1989 Golbaf ( $m_{b} 5.5$ and $1.1 \mathrm{~cm}$ displacement; Berberian and Qorashi [1994]) and also 1998 Fandogha $\left(m_{b} 5.9\right.$ and $316 \mathrm{~cm}$ displacement; Berberian et al. [2001]) earthquakes, make the diagram much scattered (Figure 7a). Residual diagram estimates 5.94 for the slope of the fitted line to the data, which is extremely high. Excluding the data with unusual surface displacements from the diagram of Figure 7 a permits us to estimate better regression and also a residual diagram with 22 events (Figure 7b). Slope of the fitted line to the residual data and standard deviation for the second estimation are -3.38 and 0.36 , respectively which are remarkably better than the first diagram. But still scattering is seen in the residual diagram. Notwithstanding we gathered all the data related to MSD in Iran, the diagram of Figure 7a is not linear. Even after excluding 8 big outliers and desultory data from 30 ones, still scattering is seen in the diagram. Our results as well as those of Papazachos et al. [2004] depart from Wells and Coppersmith [1994] relation for global earthquakes. It is important that both Papazachos et al. [2004] and Wells and Coppersmith [1994] have estimated their equations using global databases and both correspond to the maximum real (not surface) displacement. One of the possible reasons for this difference is that the magnitude range for Papazachos et al. $[2004]\left(5.0<M_{W}<9.6\right)$ database is slightly greater than that of Wells and Coppersmith [1994] $\left(4.5<M_{S}<8.1\right)$.

Regarding the fact that for a certain magnitude, fault slip is about the same for strike-slip faults and dipslip faults in continental regions [Papazachos et al. 2004] and also lack of surface slip data in Iran we did not separate the data with respect to the strike-slip and dip-slip mechanisms.

\subsection{2. $\log _{10}(S R L)-M_{W}$}

Iranian researchers have derived relation between $M_{L}$ and $M_{S}$ and maximum surface rupture length $(L)$ using 14 Iranian earthquakes (e.g., Mohajer-Ashjaei and Nowroozi [1978], $M_{L}=\log _{10}(L)+5.4$; Berberian et al. [1996, 2000], $M_{S}=1.24 \log _{10}(L)+4.99$ for $M>6.0$; Nowroozi [1985] and Berberian et al. [1996], $\left.M_{S}=1.11 \log _{10}(L)+5.19\right)$. Considering that $M_{W}$ and $M_{S}$ are nearly identical in the practical range of magnitudes for fault rupture studies in the Iranian plateau $\left(M_{S} \sim 6.0-8.0\right.$; e.g., Scordilis [2006]), the moment magnitude does not play the basic role in the Iranian relations. Also, generation of a seismic relation by converted $M_{W}$ scale is neither informative nor reliable and we could not compare our estimated equations with them. Unlike the $\log _{10}(M S D)-M_{W}$ relation, the equation estimated here (with 22 events, $5.6<M_{W}<7.4$ and standard deviation of 0.29 ) correlates well to that of Wells and Coppersmith [1994] (the $S R L$ value is max- 

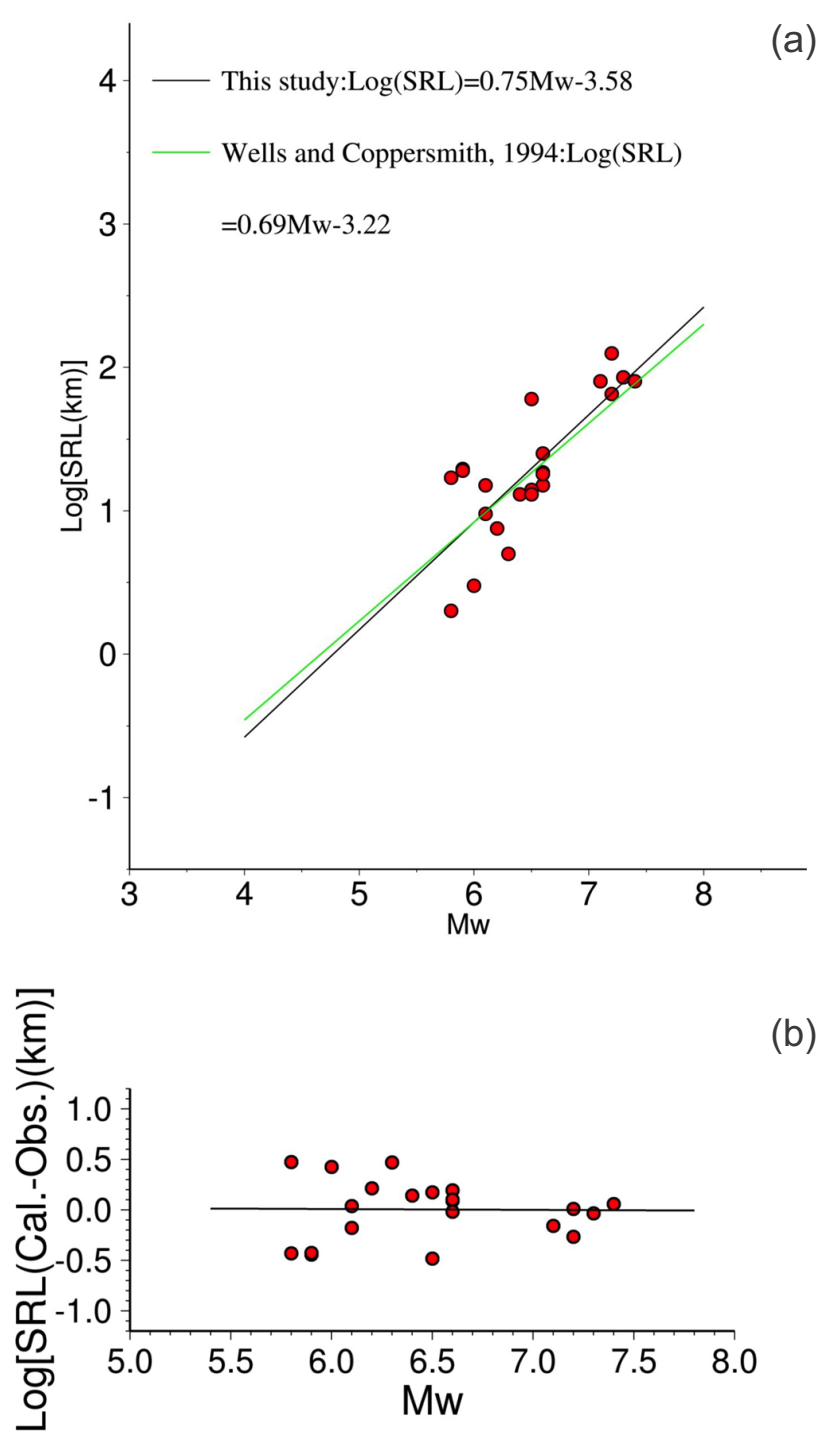

Figure 8. (a) Relation between $S R L$ and $M_{W}$ using 22 Iranian interplate earthquakes; (b) reliability test for this diagram.

imum real (not surface) rupture length) (Figure 8a). Slope for the fitted line to the events in residual plot is -0.008 (Figure $8 \mathrm{~b}$ ). It confirms a reasonable estimation between $\log _{10}(S R L)$ and $M_{W}$ relation for Iranian earthquakes.

\subsection{3. $\log _{10}(S S R L)-M_{W}$}

Wells and Coppersmith [1994] generally assumed $S R L$ to be about $75 \%$ of $S S R L$ for global earthquakes. For the first time in Iran we have suggested an equation between SSRL and $M_{W}$ using 17 continental earthquakes $\left(\log _{10}(S S R L)=0.59 M_{W}-2.29\right)$ with a standard deviation of about 0.18 . The slope of the fitted line to the earthquakes symbols applied for residual diagram is -0.012 . Here, we compare our equation with that of Papazachos et al. [2004]. We estimate more SSRL value than that of Papazachos et al. [2004]. The subsurface rupture lengths for Persian earthquakes were adopted from the aftershock surveying each have been performed by a dense local network (see Appendix 1). Ac-

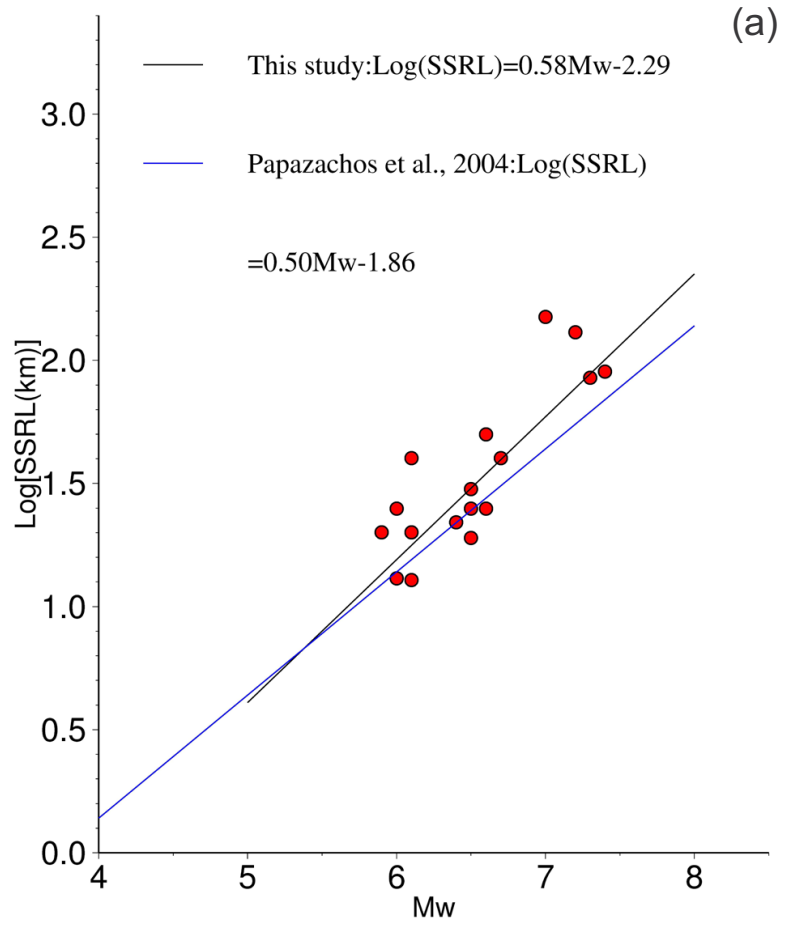

(a)

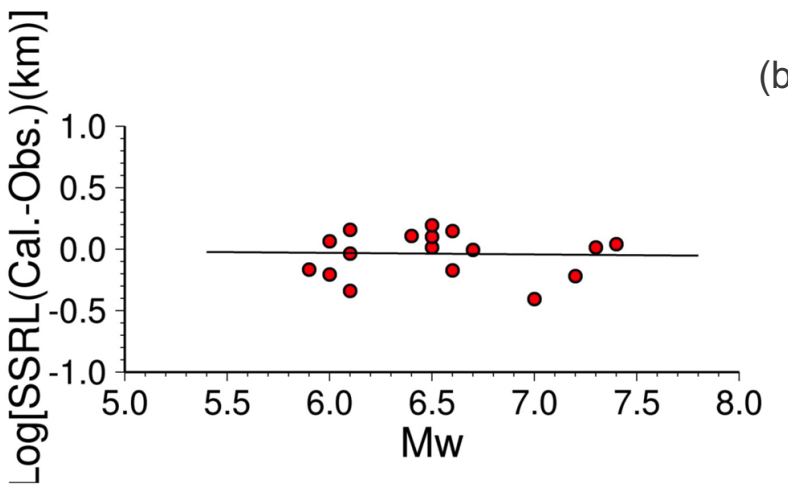

Figure 9. (a) Variation of the logarithm of the subsurface coseismic fault length, SSRL (in $\mathrm{km}$ ), as a function of $M_{W}$ for earthquakes in continental regions of Iran. (b) Residual test for the equation of Figure $9 \mathrm{a}$. Straight lines are linear fits to the data in both diagrams.

cording to the fact that the local networks data are rare not only in Iran, but also in the world, this equation is highly informative and will contain valuable information about subsurface extension for future earthquakes in Iran (Figure 9a,b).

\subsubsection{SRL/SSRL-M $M_{W}$}

We produced an equation for SSRL and $M_{W}$ for the first time in Iran using 17 continental earthquakes $\left(\log _{10}(S S R L)=0.59 M_{W}-2.29\right)$ and also an equation for $S R L$ and $M_{W}\left(\log _{10}(S R L)=0.75 M_{W}-3.59\right)$ in previous sections. Using 11 earthquakes in Iran, we want to see how SRL/SSRL ratio varies when $M_{W}$ of an event changes. Figure 10 does not show good linearity for the ratio of $S R L / S S R L$ versus $M_{W}$. The standard deviation for this regression is about 0.24 .

In seismology, $S R L$ is generally assumed to be 


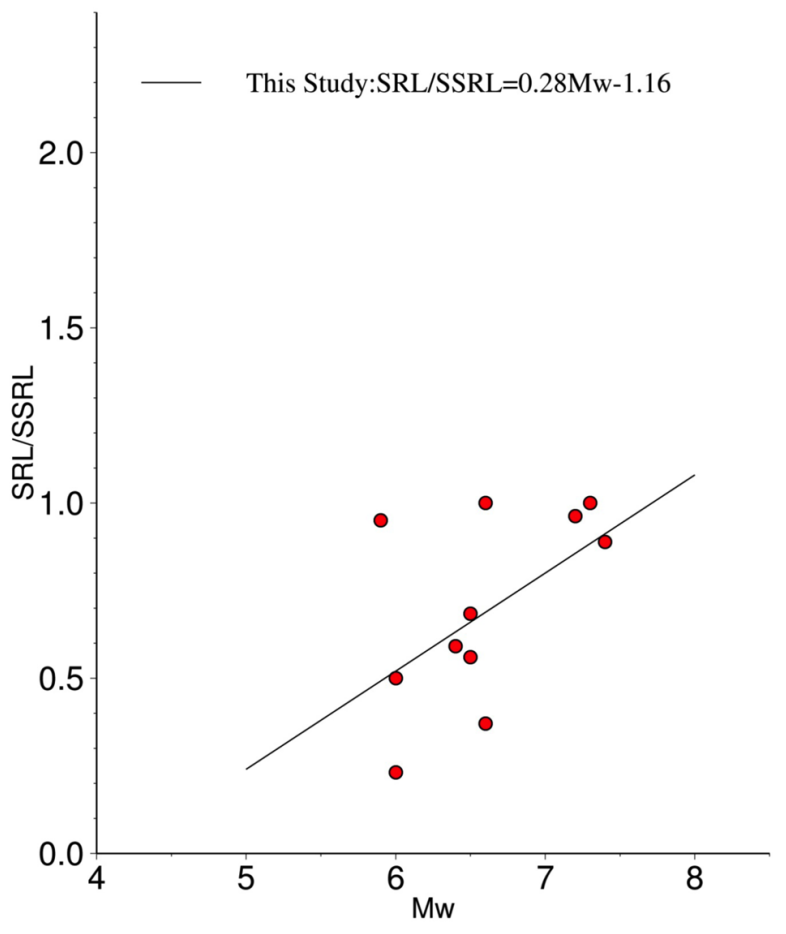

Figure 10. Ratio of $S R L / S S R L$ versus $M_{W}$ for 11 Iranian earthquakes.

about $75 \%$ of SSRL, Wells and Coppersmith [1994]. They have also depicted plot of $S R L$ to $S S R L$ ratio against $M_{W}$ of 53 events out of 421 worldwide earthquakes. They concluded that $S R L$ is a more reliable estimator for SSRL when the magnitude increases. Because of fewer number of earthquakes associated with both $S R L$ and SSRL in Iran and scattering of the data in Figure 10, we do not depict residual diagram for this equation $\left(S R L / S S R L=0.28 M_{W}-1.16\right)$. The calculated SRL/SSRL for the moderate continental earthquakes using this relation is slightly underestimated. Average of available data about rupture length for earthquakes concludes that we could generally assume $S R L$ to be about $70 \%$ of SSRL in Iran.

\subsection{5. $\log _{10}(S R L)-\log _{10}(S S R L)$}

Generally, in seismology the length of rupture at the surface is assumed to be smaller than SSRL [e.g., Wells and Coppersmith 1994]. They used the source parameters of 421 global intra-plate and inter-plate earthquakes (after 1900; $M>5.0$ ) and revealed that the ratio of SRL to SSRL of a fault increases when the magnitude of the corresponding earthquake increases. A little number of events within 53 global earthquakes investigated by Wells and Coppersmith [1995] has SRL greater than its SSRL. Here, we generally examine this idea for the Iranian earthquake faults.

The symbols of Figure 11 as well as the fitted line to the symbols (the black line corresponding to the equation of $\left.\log _{10}(S R L)=1.29 \log _{10}(S S R L)-0.65\right)$ and

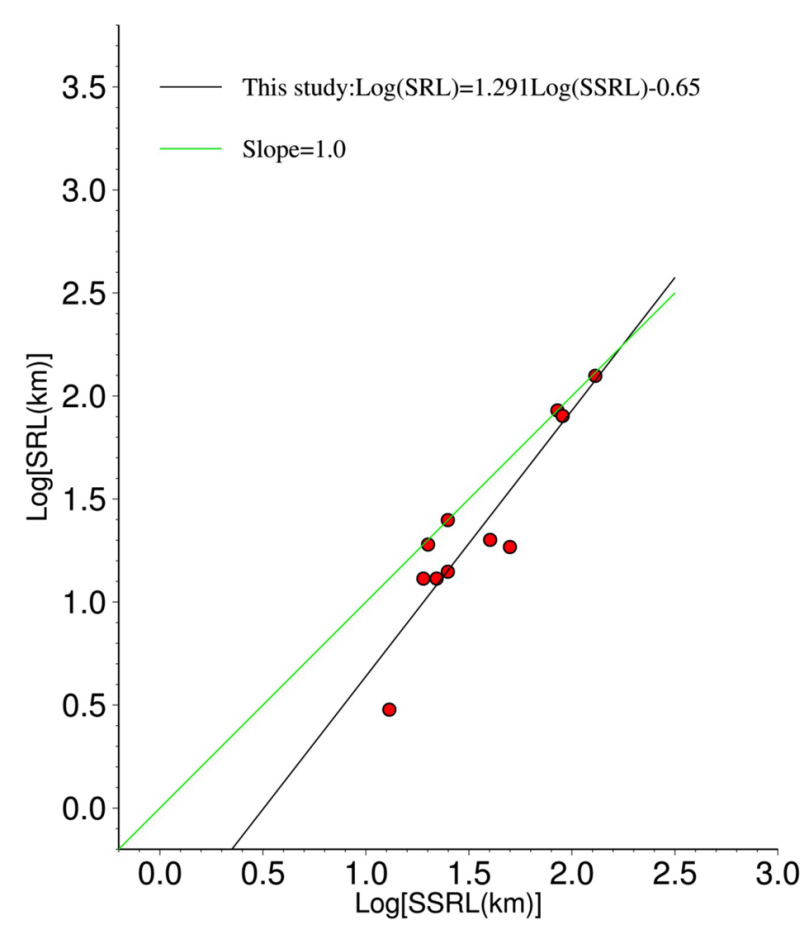

Figure 11. Diagram of $S R L$ versus $S S R L$ estimated from the distribution of source parameters for 11 continental earthquakes in Persia.

green line (slope $=1.0)$ manifestly reveal that our study is slightly different from Wells and Coppersmith [1994]. Figure 11 shows that all the earthquakes applied for plotting the diagram have SSRL greater than their surface ruptures (see the line with slope 1).

\subsection{6. $\log _{10}(M S D)-\log _{10}(S R L)$}

There is a remarkable difference between MSD$S R L$ relation, estimated for the Iranian earthquakes (Figure 12a) and the global equation of Wells and Coppersmith [1994]. Figure 12a was depicted using 26 Persian earthquakes with a relatively high standard deviation (0.65) and a considerable amount of scattering. Notwithstanding near zero slope $(-0.003)$ of the residual diagram, the relation could prudently be used for estimation of rupture characteristics for the earthquakes in Iran (Figure 12b).

\section{Discussion and conclusion}

Relationships between source parameters for large earthquakes in Iran have rarely been investigated. The present work has computed seismic relations using a relatively complete catalogue gathered from Persian earthquakes. Using a large amounts of seismological (magnitude and SSRL) and geological data (SRL and $M S D$ ), source behaviors for 436 earthquakes with $M \geq 5.0$ were investigated. Empirical relationships between $M_{0}$ and other classical magnitude scales $\left(m_{b}, M_{S}\right.$ and $\left.M_{L}\right)$ were derived using seismic databases of ISC, IIEES and IGUT. The empirical relationships in this study demon- 

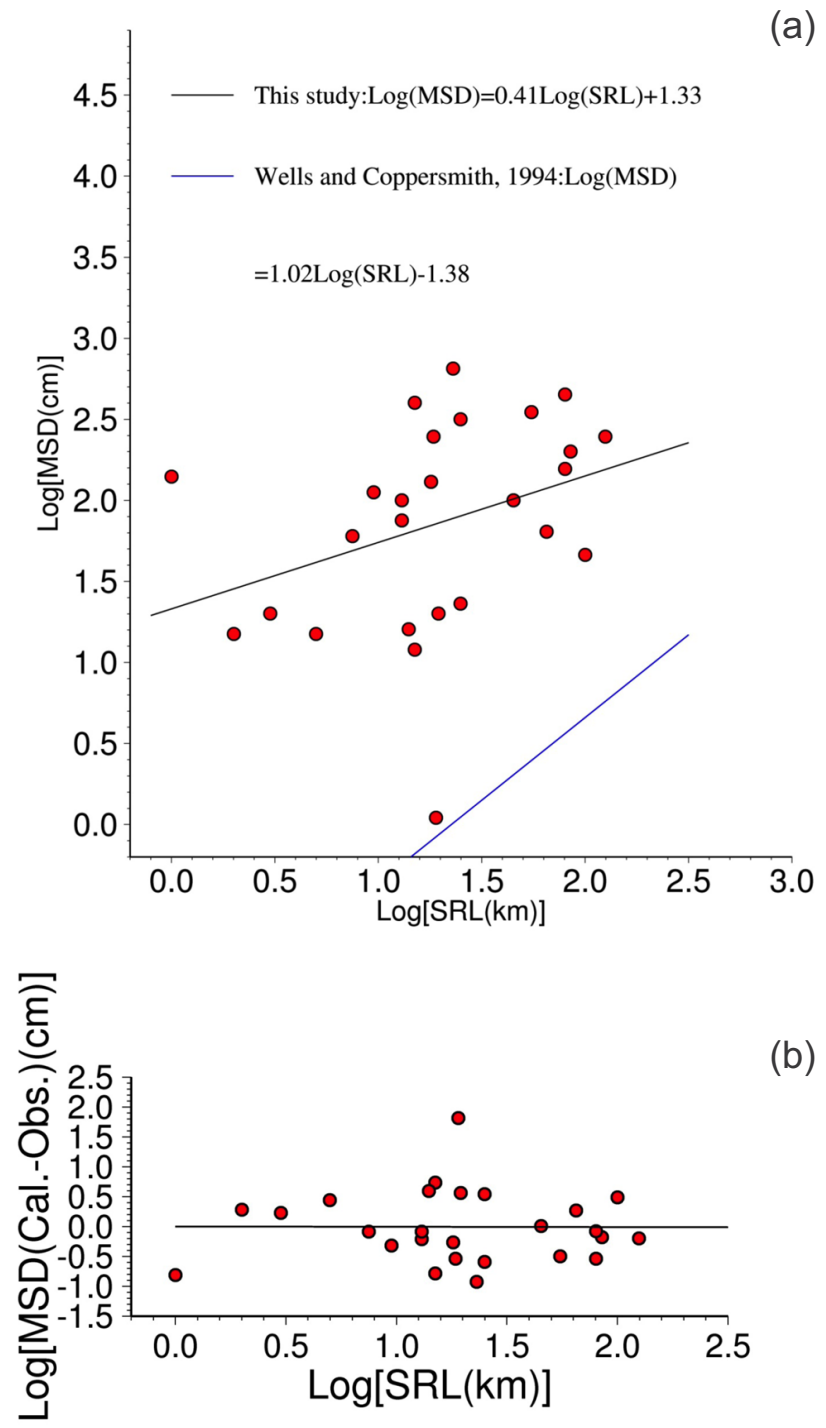

Figure 12. (a) Regression for relation between $\log _{10}(M S D)$ and $\log _{10}(S R L)$ using 26 Iranian earthquakes from 1900 to 2013 (the black and blue lines indicate to this study and Wells and Coppersmith [1994], respectively); (b) residual diagram for equation of Figure 12a.

strate a relatively robust correlation between the magnitude and various rupture parameters, which helps to confidently use these relationships for estimate either magnitudes or rupture parameters. The comparisons indicate that our models correlate fairly to the estimations of some regional and worldwide studies. Analysis of data of various magnitudes shows that regressions containing many number of the data points, are more reliable in comparison to the diagrams with less number of the events. The equations for SSRL is appropriate where it is difficult to estimate the deep behaviors of coseismic faults, such as buried or blind faults for example in the Zagros area in Iran.

$S R L-M_{W}$ relation indicates that the Iranian earthquakes of large magnitude do not necessarily have large rupture lengths (e.g., $\approx 56 \mathrm{~km}$ rupture length calculated for M 7.1 event unlike 1997 Zirkuh-e Qaen earthquake (M 7.1) with $>100 \mathrm{~km}$ rupture). A possible explanation for this underestimation is that for a certain magnitude in continental regions, fault length is slightly greater for strike-slip events than dip-slip earthquakes [Papazachos et al. 2004]. Separating the data for strike-slip and dipslip events decreases the uncertainty in magnitude estimations from $S R L$ of the earthquakes.

We compared our derived empirical equations with that of the other studies in the literature. $M_{0}-m_{b}$, $M_{0}-M_{S}, M_{N}-M_{L}$ and $M S D-M_{W}$ equations have a well correlation with the worldwide and also regional relations calculated by Nuttli [1983a], Karimiparidari et al. [2013] and Papazachos et al. [2004], respectively. Also, $M_{0}-M_{S}$ and $M_{0}-M_{L}$ relations show good resemblance with a regional work in Taiwan [Chen et al. 2007]. According to the similarity between the results of this study and Taiwanese, it could be concluded that Iranian seismotectonic properties are not so different from Taiwan area, which is belonging to a region of Southeast Asia. We mainly confirm the results of Wells and Coppersmith [1994] for rupture length of the global historical and instrumental earthquakes. Also, we explored that the ratio of SRL/SSRL slightly increases when the magnitude of corresponding earthquake increases.

However, some relations like $M_{W}-M_{N}$ and $M_{N}-M_{L}$, which remarkably depart from scarce regional works (Atkinson [1993] for America, and Sonley and Atkinson [2005] for Canada) were found. This might imply that the tectonic conditions, accumulation of seismic stress energy, and crustal properties of the Iranian territory do not behave exactly like the North American region.

If we consider standard deviation under 0.35 [Wells and Coppersmith 1994], $M_{0}-M_{S}, M_{W}-M_{N}, M_{N}-M_{L}, S R L-$ $M_{W}, S S R L-M_{W}, S R L / S S R L-M_{W}$ and SRL/SSRL relations were especially well calculated. The calculations for $M S D$ relations are mainly associated with high standard deviations. One possible explanation for this problem is extraordinary surface displacements measured for moderate earthquakes in Persia like 1998 Fandogha $\left(\approx 320 \mathrm{~cm}\right.$ maximum slip for $M_{W} 6.6$; Berberian et al. [2001]) earthquake.

Acknowledgements. Thanks to the Institute of Geophysics, the University of Tehran and International Earthquake Engineering and Seismology of Iran for their online earthquake databases.

\section{References}

Aki, K. (1966). Generation and propagation of LG waves from the Niigata earthquake of June 16, 1964. 2. Estimation of earthquake movement, released energy, and stress-strain drop from G-wave spectrum, B. Earthq Res. I. Tokyo, 44, 23-88.

Aki, K. (1967). Scaling law of seismic spectrum, J. Geophys. Res., 72, 1217-1231. 
Ambraseys, N.N. (1988). Magnitude - fault length relationships for earthquakes in the Middle East, In: W.H. Lee, H. Meyers and K. Shimazaki (eds.), Historical Seismograms and Earthquakes of the World, Acad. Press Inc., 309-310.

Ambraseys, N., and C. Melville (1982). A History of Persian Earthquakes, Cambridge University Press.

Ambraseys, N., and J. Jackson (1998). Faulting associated with historical and recent earthquakes in the eastern Mediterranean region, Geophys. J. Int., 133, 390-406.

Atefi, S., and M.R. Gheitanchi (2010). Investigation of source characteristics of the 1997 Ardabil Earthqualce, 14th Iranian Conference of Geophysics, 1220-1223 (in Persian).

Atkinson, G.M. (1993). Earthquake source spectra in eastern North America, B. Seismol. Soc. Am., 94, 1079-1095.

Baruah, S., P.K. Bora, R. Duarah, A. Kalita, R. Biswas, N. Gogoi and J.R. Kayal (2012). Moment magnitude - local magnitude relationship for the earthquakes of the Shillong-Mikir plateau, or the eastern India Region: a new perspective, Geomatics Natural Hazards and Risk, 3 (4), 365-375; doi:10.1080/ 19475705. 2011.596577.

Berberian, M. (1976a). Documented earthquake faults of Iran, Geol. Surv. Iran, 39, 143-186.

Berberian, M. (1976b). The 1962 earthquakes and earlier deformation along the Ipak earthquake fault, Geol. Surv. Iran, 39, 419-427.

Berberian, M., and J.S. Tchalenko (1976a). Field study and documentation of the 1930 Salmas (ShahpourSalmas) earthquake, Geol. Surv. Iran, 39, 271-342.

Berberian, M., and J.S. Tchalenko (1976b). Earthquakes of southern Zagros (Iran): Bushehr region, Geol. Surv. Iran, 39, 343-369.

Berberian, M., and I. Navai (1978). Naghan (Chahar Mahal-e Bakhtiari-High Zagros, Iran) earthquake of 6 April 1977. A preliminary field report and a seismotectonic discussion, Annali di Geofisica, 31 (1), 5-27.

Berberian, M., and D. Papastamatiou (1978). Khorgu (North Bandar-e Abbas, Iran) earthquake of March 21, 1977: A preliminary field report and a seismotectonic discussion, B. Seismol. Soc. Am., 68 (2), 411-428.

Berberian, M. (1979). Tabas-e Golshan (Iran) catastrophic earthquake of 16 Sep. 1978; a preliminary field report, Disasters, 2 (4), 207-219.

Berberian, M., I. Asudeh and S. Arshadi (1979). Surface rupture and mechanism of the Bob-Tangol (Southeastern Iran) earthquake of 19 Dec. 1977, Earth Planet. Sc. Lett., 42, 456-462.

Berberian, M. (1982). Aftershock tectonics of the 1978 Tabas- e-Golshan (Iran) earthquake sequence: a doc- umented active thin- and thick-skinned tectonic' case, Geophys. J. R. astr. Soc., 68, 499-530.

Berberian, M., J.A. Jackson, M. Ghorashi and M.H. Kadjar (1984). Field and teleseismic observation of the 1981 Golbaf-Sirch earthquakes in SE Iran, Geophys. J. Int., 77 (3), 809-838.

Berberian, M., M. Qorashi, J.A. Jackson, K. Priestley and T. Wallace (1992). The Rudbar-Tarom earthquake of June 20, 1990 in NW Persia: Preliminary field and seismological observations, and its tectonic significance, B. Seismol. Soc. Am., 82, 1726-1755.

Berberian, M., and M. Qorashi (1994). Coseismic faultrelated folding during the south Golbaf earthquake of November 20, 1989, in southeast Iran, Geology, 22, 531-534.

Berberian, M. (1995). Master blind thrust faults hidden under the Zagros folds: active basement tectonics and surface morphotectonic, Tectonophysics, 241, 193-224.

Berberian, M., M. Ghorashi, M. Talebian and J. ShojaTaheri (1996). Seismotectonic and earthquake-fault hazard investigations in the Semnan region (Contribution to the Seismotectonics of Iran, Part VII), Geol. Surv. Iran, 63, 266 pp. (in Persian).

Berberian, M. (1997). Seismic source of the transcaucasian historical earthquakes. Historical and prehistorical earthquakes in Caucasus, Academic Publishers, Netherlands, 233-311.

Berberian, M., M. Qurashi, J. Shoja-Taheri and M. Talebian (2000). Seismotectonics and earthquakefault hazard investigations in the Mashhad-Neyshabour region (Contribution to the seismotectonics of Iran, Part VIII), Geol. Surv. Iran, 72, 233 pp. (in Persian). Berberian, M., M. Qorashi, J.A. Jackson, E. Fielding, B.E. Parsons, K. Priestley, M. Talebian, R. Walker, T.J. Wright and E. Baker (2001). The 1998 March 14 Fandoqa earthquake $M=6.6$ in Kerman, southeast Iran: Re-rupture of the 1981 Sirch earthquake fault, triggering of slip on adjacent thrusts, and the active tectonics of the Gowk fault zone, Geophys. J. Int., 146 (2), 371-398.

Berberian, M., and R. Walker (2010). The RudbarTarom 7.3 earthquake of 1990 June 20; seismotectonics, coseismic and geomorphic displacements, and historic earthquakes of the western 'High-Alborz’, Iran, Geophys. J. Int.; doi:10.1111/j.1365246X.2010.04705.

Bethmann F., N. Deichmann and P.M. Mai (2011). Scaling relations of local magnitude versus moment magnitude for sequences of similar earthquakes in Switzerland, B. Seismol. Soc. Am., 101, 515-534; doi:0.1785/ 0120100179.

Bonilla, M., R. Mark and J. Lienkaemper (1984). Statis- 
tical relations among earthquake magnitude, surface length and surface fault displacements, B. Seismol. Soc. Am., 74, 2379-2411.

Bormann, P., R. Liu, X. Ren, R. Gutdeutsch, D. Kaiser and S. Castellaro (2007). Chinese National Network Magnitudes, Their Relation to NEIC Magnitudes, and Recommendations for New IASPEI Magnitude Standards, B. Seismol. Soc. Am., 97 (1B), 114-127; doi: $10.1785 / 0120060078$.

Chen, K., W.G. Huang and J.H. Wang (2007). Relationships Among Magnitudes and Seismic Moment of Earthquakes in the Taiwan Region, Terr. Atmos. Ocean. Sci., 18 (5), 951-973.

Cheng, S.N., and Y.T. Yeh (1989). Catalog of earthquakes in Taiwan from 1604 to 1988, Open File Rept., Inst. Earth Sci., Acad. Sin., 255 pp. (in Chinese).

Das, R., H.R. Wason and M.L. Sharma (2011). Global regression relations forcon version of surface wave and body wave magnitudes to moment magnitude, Nat. Hazards, 59, 801-810; doi:10.1007/s11069-0119796-6.

Das, R., H.R. Wason and M.L. Sharma (2012). Homogenization of Earthquake Catalog for Northeast India and Adjoining Region, Pure Appl. Geophys., 169, 725-731; doi:10.1007/s00024-011-0339-6.

Deniz, A., and M.S. Yucemen (2010). Magnitude conversion problem for the Turkish earthquake data, Natural Hazards, 55, 333-352; doi:10.1007/s11069010-9531-8.

Faridi, M., and A. Sartipi (2012). The 2012 Ahar-Varzaghan earthquakes report, Geol. Surv. Iran, internal report (in Persian).

Fatemi, J., B. Akashehand and G. Hamidi (1998). The 1989/11/20 Golbaf Earthquake and its aftershocks, J. Earth and Space Physics, University of Tehran, Iran, 24 (1/2), 11-15 (in Persian).

Fuller, W.A. (1987). Measurement Error Models, Wiley, New York, 440 pp.

Gardner, J.K., and L. Knopoff (1974). Is the sequence of earthquakes in Southern California, with aftershocks removed, Poissonian?, B. Seismol. Soc. Am., 64 (5), 1363-1367.

Gasperini, P., B. Lolli, G. Vannucci and E. Boschi (2012). Calibration ofmoment magnitude estimates for the European-Mediterranean and Italian regions, Geophys. J. Int., 190, 1733-1745; doi:10.1111/j.1365246X.2012.05575.x.

Gasperini, P., B. Lolli and G. Vannucci (2013a). Empirical Calibration of Local Magnitude DataSets Versus Moment Magnitude in Italy, B. Seismol. Soc. Am., 103 (4), 2227-2246; doi:10.1785/0120120356.

Gasperini, P., B. Lolli and G. Vannucci (2013b). Body wave magnitude $m_{b}$ is a good proxy of moment magnitude Mw for small earthquakes $\left(m_{b}<4.5-5.0\right)$, Seismol. Res. Lett., 84 (6), 932-937; doi: 10.1785/ 022 0130105.

Gheitanchi, M.R., A. Fatehi and A.Sadidkhoy (1998a). Investigations of the February 4th 1997 Bojnourd, North-East Iran, earthquake sequence, J. Earth and Space Physics, University of Tehran, Iran, 24 (1/2), 29-35.

Gheitanchi, M.R., D. Shafiei and E. Bayramnajad (1998b). The February 28, 1997, Ardabil, Northwest Iran, Earthquake and its Aftershocks, J. Earth and Space Physics, University of Tehran, Iran, 24 (1/2), 1-9.

Gheitanchi, M.R. (2004). The June 222002 Changoureh-Avaj earthquake in Qazvin province, north central Iran, J. Earth and Space Physics, University of Tehran, Iran, 30 (1), 23-30.

Gheitanchi, M.R., and M. Raeesi (2004). Analysis of the 1997 Zirkuh (Ghean-Birjand) aftershock sequence in east-central Iran, Acta Seismologica Sinica, 17 (1) 38-46; doi:1000-9116(2004)01-0038-09.

Grünthal, G., D. Stromeyer and R. Wahlström (2009). Harmonization check of $M_{w}$ within the central, northern, and north-western European earthquake catalog (CENEC), J. Seismol., 13, 613-632; doi:10.10 07/s10950-009-9154-2.

Grünthal, G., and R. Wahlström (2012). The EuropeanMediterranean Earthquake Catalog (EMEC) for the last millennium, J. Seismol., 16, 535-570; doi:10.1007/ s10950-012-9302-y.

Gutenberg, B., and C.F. Richter (1956). Earthquake magnitude, intensity, energy and acceleration (second paper), B. Seismol. Soc. Am., 46, 105-145.

Hanks, T.C., and H. Kanamori (1979). A moment magnitude scale, J. Geophys. Res., 84, 2348-2350.

Hessami, K., F. Jamali and H. Tabassi (2003). Map of Major Active Faults of Iran, Tech. rep., International Institute of Earthquake Engineering and Seismology, Iran; http:/ / www.iiees.ir.

Hollingsworth, J., J. Jackson, R. Walker, M. Gheitanchi and M. Bolourchi (2006). Strike-slip faulting, rotation, and along-strike elongation in the Kopeh Dagh mountains, NE Iran, Geophys. J. Int., 166, 1161-1177.

Jackson, J.A., and T.J. Fitch (1979). Seismotectonic implications of relocated aftershock sequences in Iran and Turkey, Geophys. J. R. Astr. Soc., 57, 209-229.

Jackson, J.A., and T.J. Fitch (1981). Basement faulting and focal depth of the larger earthquakes in the $\mathrm{Za}$ gros mountains (Iran), Geophys. J. R. Astr. Soc., 64, 561-586.

Jackson, J., et al. (2006). Seismotectonic, rupture process, and earthquake hazard aspects of the 2003 December 26 Bam, Iran, earthquake, Geophys. J. Int., 166, 1270-1292. 
Kanamori, H., and D.C. Anderson (1975). Theoretical basis of some empirical relations in seismology, B. Seismol. Soc. Am., 65, 1073-1096.

Kanamori, H. (1979). Seismological aspects of intracontinental earthquakes, Proc. Inter. Research Conf. on Intra-Continental Earthquakes, September 1721, Ohrid, Yugoslavia, 117-127.

Karakaisis, G.F., C.B. Papazachos and E.M. Scordilis (2010). Seismic Sources and Main Seismic Faults in the Aegean and Surrounding Area (Proceedings of the 12 International Congress, Patras, May 2010), Bull. Geol. Soc. Greece.

Karimiparidari, S., M. Zaré, H. Memarian and A. Kijko (2013). Iranian earthquakes, a uniform catalog with moment magnitudes, J. Seismol., 17 (3), 897-911.

Krystek, M., and M. Anton (2007). A weighted total least-squares algorithm for fitting a straight line, Meas. Sci. Tech., 22, 3438-3442.

Maggi, A., J.A. Jackson, K. Priestley and C. Baker (2000). A re-assessment of focal depth distributions in southern Iran, the Tien Shan and northern India: do earthquakes really occur in the continental mantle?, Geology, 28 (6), 495-498.

Mohajer-Ashjaei, A., and A.A. Nowroozi (1978). Observed and probable intensity zoning of Iran, Tectonophysics, 49, 149-160.

Murotani, S., K. Satake and Y. Fujii, (2013). Scaling relations of seismic moment, rupture area, average slip, and asperity size for $M \sim 9$ subduction-zone earthquakes, Geophys. Res. Lett., 40, 5070-5074; doi:10.1002/grl.50976, 2013.

Nemati, M., and M. Gheitanchi (2011). Analysis of 2005 Dahuieh (Zarand) aftershocks sequence in Kerman province, J. Earth and Space Physics, University of Tehran, Iran, 37, 1-9.

Nemati, M., B. Oveisi, M. Foroutan and M.J. Bolourchi (2012). Geomorphology and seismology of Mw 5.8 Koodian, Southeast Zagros, Geol. Surv. Iran, 85, 8188 (in Persian).

Nemati, M. (2013). Some aspects about seismology of 2012 August 11 Ahar-Varzaghan (Azarbayjan, NW Persia) earthquakes sequences, Journal of Sciences, Islamic Republic of Iran, 24 (3), 229-241; ISSN:10161104.

Nemati, M. (2014) An appraisal of aftershocks behavior for large earthquakes in Persia, J. Asian Earth Sci., 79, Part A, 432-440; doi:10.1016/j.jseaes, 2013.10.015.

Nissen, E., M. Ghorashi, J. Jackson, P. Parsons and M. Talebian (2007). The 2005 Qeshm Island ea rthquake (Iran) a link between buried reverse faulting and surface folding in the Zagros Simply Folded Belt?, Geophys. J. Int., 171, 326-338.

Nissen, E., F. Yamini-Fard, M. Tatar, A. Gholamzadeh,
E. Bergman, J.R. Elliott, J.A. Jackson and B. Parsons (2010). The vertical separation of mainshock rupture and microseismicity at Qeshm Island in the Zagros Simply Folded Belt, Iran, Earth Planet. Sc. Lett., 296, 181-194.

Nowroozi, A.A., A.M. Mohajer-Ashjai, M.R. Rad and A.A. Izadpanah (1977). The mainshock and aftershocks of the March 21, 1977 earthquake in the Khurgu region, Atomic Energy Authority of Iran, internal report.

Nowroozi, A.A. (1985). Empirical relationships between magnitudes and fault parameters for earthquakes in Iran, B. Seismol. Soc. Am., 75 (5), 1327-1338.

Nuttli, O.W. (1973). Seismic wave attenuation and magnitude relations for eastern North America, J. Geophys. Res., 78, 876-885.

Nuttli, O.W. (1983a). Empirical magnitude and spectral scaling relations for mid-plate and plate-margin earthquakes, Tectonophysics, 93, 207-223.

Nuttli, O.W. (1983b). Average source-parameter relations for mid-plate earthquakes, B. Seismol. Soc. Am., 13, 519-535.

Papazachos, B.C., and C.B. Papazachou (2003). The earthquakes of Greece, Ziti Publications, Thessaloniki, $273 \mathrm{pp}$.

Papazachos, B.C., E.M. Scordilis, D.G. Panagiotopoulos, C.B. Papazachos and G.F. Karakaisis (2004). Global relations between seismic fault parameters and moment magnitude of earthquakes (Proceedings of the 10th International Congress, Thessaloniki, April 2004), Bull. Geol. Soc. Greece, 36.

Rezapour, M. (1991). Study of mechanism and aftershocks of 1990 Roudbar-Manjil earthquake, Geophysics Institute, University of Tehran, Iran, M.Sc. thesis (in Persian).

Rezapour, M. (2005). Magnitude scale in the Tabriz seismic network, J. Earth Space Phys., 31 (1), 13-21.

Rezapour, M. (2009). Analysis of the causative fault during Silakhor earthquake, March 31, 2006 in Lorestan province, Iran. J. Geophysics, 3 (1), 75-89 (in Persian).

Richter, C.F. (1935). An instrumental earthquake magnitude scale, B. Seismol. Soc. Am., 25, 1-32.

Ristau, J. (2009). Comparison of Magnitude Estimates for New Zealand Earthquakes: Moment Magnitude, Local Magnitude, and Teleseismic Body-Wave Magnitude, B. Seismol. Soc. Am., 99 (3), 1841-1852; doi:10. $1785 / 0120080237$.

Scordilis, E.M. (2006). Empirical global relations converting $M_{S}$ and $m_{b}$ to moment magnitude, J. Seismol., $10,225-236$.

Shahrabi, T., and G.h. Dolouei (2009). Seismicity properties of the Silakhour-Boroujerd plane based on locally recorded data, Eng. Geol. J., 3 (2), 697-716. 
Shahvar, M.P., M. Zare and S. Castellaro (2013). A Unified Seismic Catalog for the Iranian Plateau (19002011), Seismol. Res. Lett., 84 (2), 233-249.

Shin, T.C. (1986). Duration-magnitude correction for Taiwan Telemetered Seismographic Network, Bull. Inst. Earth Sci., Acad. Sin., 6, 109-120.

Shoja-Taheri, J., S. Naserieh and H. Ghofrani (2007). $M_{L}$ and $M_{W}$ Scales in the Iranian Plateau Based on the Strong-Motion Records, B. Seismol. Soc. Am., 97 (2), 661-669.

Smith, G.C., and C.h. Stock (2000). Evidence for different scaling of earthquake source parameters for large earth-quakes depending on faulting mechanism, Geophys. J. Int., 143, 157-169.

Sonley, E., and G. Atkinson (2005). Emperical relationship between moment magnitude and Nuttli magnitude for small-magnitude earthquakes in Southeastern Canada, Seismol. Res. Lett., 26 (6), 726-755.

Stromeyer, D., G. Grünthal and R. Wahlström (2004). Chi-square regression for seismic strength parameter relations, and their uncertainties, with applications to an $M_{w}$ based earthquake catalog for central, northern and north-western Europe, J. Seismol., 8 (1), 143-153.

Talebian, M., E. Fielding, G. Funning, M. Qorashi, J. Jackson, H. Nazari, B. Parsons, K. Priestley, P.A. Rosen, R. Walker and T.J. Wright (2004). The 2003 Bam (Iran) earthquake: rupture of a blind strike-slip fault, Geophys. Res. Lett., 31, L11611.

Talebian, M., J. Biggs, M. Bolourchi, A. Copley, A. Ghassemi, M. Ghorashi, J. Hollingsworth, J. Jackson, E. Nissen, B. Oveisi, B. Parsons K. Priestley and A. Saiidi (2006). The Dahuiyeh (Zarand) earthquake of 2005 February, 22 in central Iran, Geophys. J. Int., 164, 137-148.

Tatar, M., D. Hatzfeld, A.S. Moradi and A. Paul (2005). The 2003 December 26 Bam earthquake (Iran), M 6.6, aftershock sequence, Geophys. J. Int., 163, 90-105.

Tatar, M., J. Jackson, D. Hatzfeld and E. Bergman (2007). The 2004 May 28 Baladeh earthquake $\left(M_{w}\right.$ 6.2) in the Alborz, Iran: overthrusting the South Caspian Basin margin, partitioning of oblique convergence and the seismic hazard of Tehran, Geophys. J. Int., 170, 249-261.

Tchalenko, J.S. (1975). Seismicity and structure of the Kopeh Dagh (Iran, USSR), Phil Trans. Roy. Soc., London, 278, 1-25.

Tocher, D. (1958). Earthquake energy and ground breakage, B. Seismol. Soc. Am., 48, 147-153.

Utsu, T., and A. Seki (1954). A relation between the area of aftershock region and the energy of mainshock, J. Seismol. Soc. Japan, 24, 233-240.

Walker, R.T., K. Priestley, M.J. Andalibi, M.R. Ghei- tanchi, J.A. Jackson and S. Karegar (2005a). Seismological and field observations from the 1990 November 6 Furg (Hormozgan) earthquake: a rare case of surface rupture in the Zagros mountains of Iran, Geophys. J. Int., 163, 567-579.

Walker, R.T., E. Bergman, J. Jackson, M. Ghorashi and M. Talebian (2005b). The 2002 June 22 Changureh (Avaj) earthquake in Qazvin province, northwest Iran: epicentral relocation, source parameters, surface deformation and geomorphology, Geophys. J. Int., 160, 707-720.

Walker, R.T., E.A. Bergman, W. Szeliga and E.J. Fielding (2011). Insights into the 1968-1997 Dasht-eBayaz and Zirkuh earthquake sequences, eastern Iran, from calibrated relocations, InSAR and highresolution satellite imagery, Geophys. J. Int.; doi:10. 1111/j.1365-246X.2011.05213.x.

Walker, R.T., E.A. Bergman, J.R. Elliott, E.J. Fielding, A.R. Ghods, M. Qorashi, J. Jackson, H. Nazari, M. Nemati, B. Oveisi, M. Talebian and R.J. Walters (2013). The 2010-2011 South Rigan (Baluchestan) earthquake sequence and its implications for distributed deformation and earthquake hazard in southeast Iran, Geophys. J. Int., 1-26; doi:10.1093/ gji/ggs109.

Wang, J.H., C.C. Liu and Y.B. Tsai (1989). Local magnitude determined from a simulated Wood-Anderson seismograph, Tectonophysics, 166, 15-26.

Wang, J.H., and S.S. Ou (1998). On scaling of earthquake faults, B. Seismol. Soc. Am., 88, 758-766.

Wells, D.L., and K.J. Coppersmith (1994). New empirical relationships among magnitude, rupture length, rupture width, rupture area and surface displacement, B. Seismol. Soc. Am., 84, 974-1002.

Wesnousky, S.G. (1986). Earthquake, quaternary faults and seismic hazard in California, J. Geophys. Res., 91, 12587-12631.

Wessel, P., and W.H.F. Smith (1998). New improved version of Generic Mapping Tools released, EOS, Trans. AGU, 79 (47), 579; www.soest.hawaii.edu/gmt.

Yenier, E., O. Erdoğan and S. Akkar (2008). Empirical relationships for magnitude and source-to-site distance convergence using recently compiled Turkish strong-ground motion database, The 14th World Conference on Earthquake Engineering, October 12-17, 2008, Beijing, China.

Zafarani, H., and M.Soghrat (2012). Simulation of Ground Motion in the Zagros Region of Iran Using the Specific Barrier Model and the Stochastic Method, B. Seismol. Soc. Am., 102, 2031-2045.

Zare, M., et al. (2014). Recent developments of the Middle East catalog, J. Seismol.; doi:10.1007/s10950014-9444-1. 


\section{Web references}

Harvard University, Department of Geological Sciences,

Centroid Moment Tensor catalogue:

http:/ / wwwglobalcmt.org/CMTsearch.html.

International Seismological Center, ISC catalogue:

http:/ / www.isc.ac.uk.

International Seismological Center, Engdahl catalogue:

http:/ / www.isc.ac.uk.

Institute of Geophysics University of Tehran, IGUT

catalogue: http: / / irsc.ut.ac.ir.

International Institute of Earthquake Engineering and Seismology of Iran, IIEES catalogue:

http://iiees.ac.ir.

International Association of Seismology and Physics of the Earth's Interior (IASPEI):

http:/ / www.iaspei.org.

Origin Software: http:/ / www.microcal.com.

Corresponding author: Majid Nemati,

Shahid Bahonar University of Kerman, Department of Geology,

Kerman, Iran; email: nematimajid_1974@uk.ac.ir.

(C) 2015 by the Istituto Nazionale di Geofisica e Vulcanologia. All

rights reserved. 


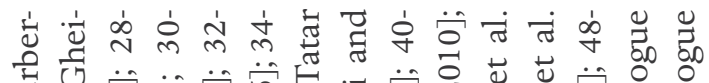

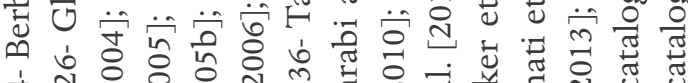

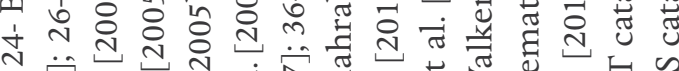

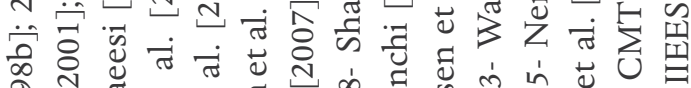

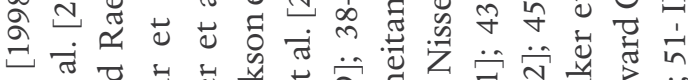
तं 屯

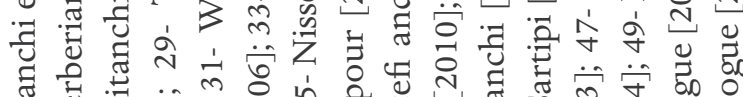
预 岱

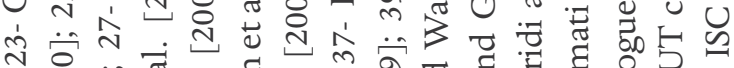

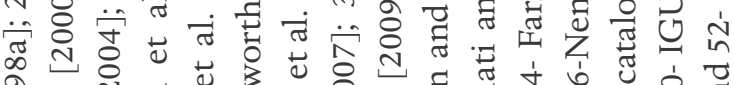

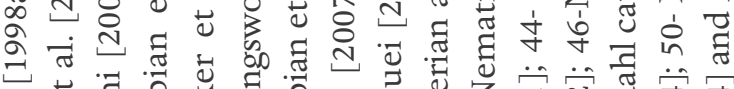

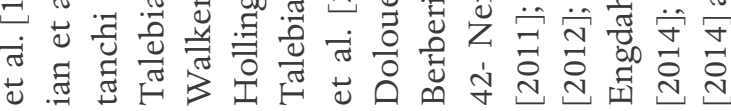

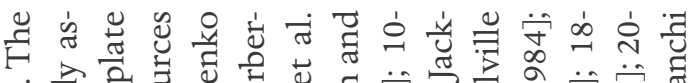

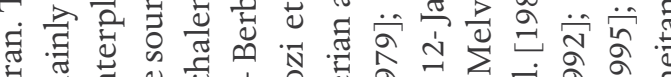

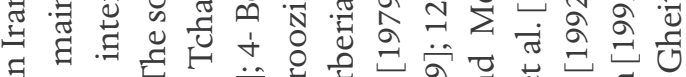

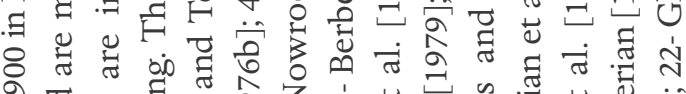

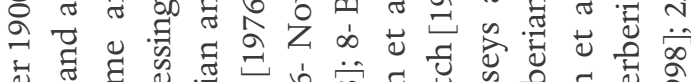

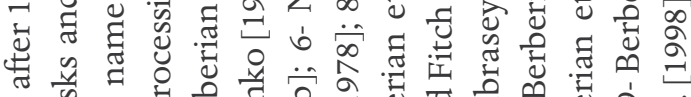

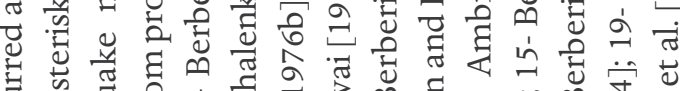

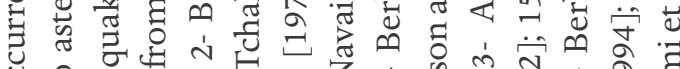

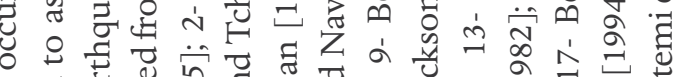

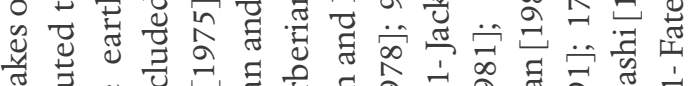

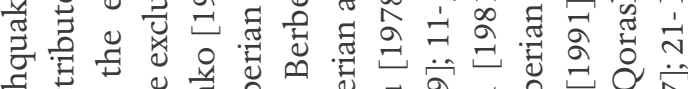

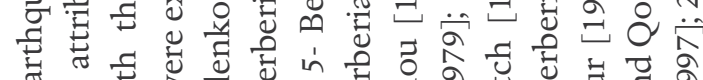
- चौ

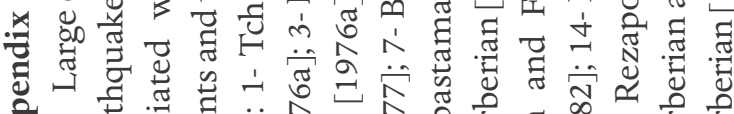

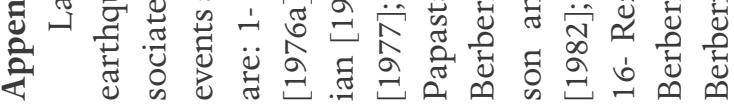

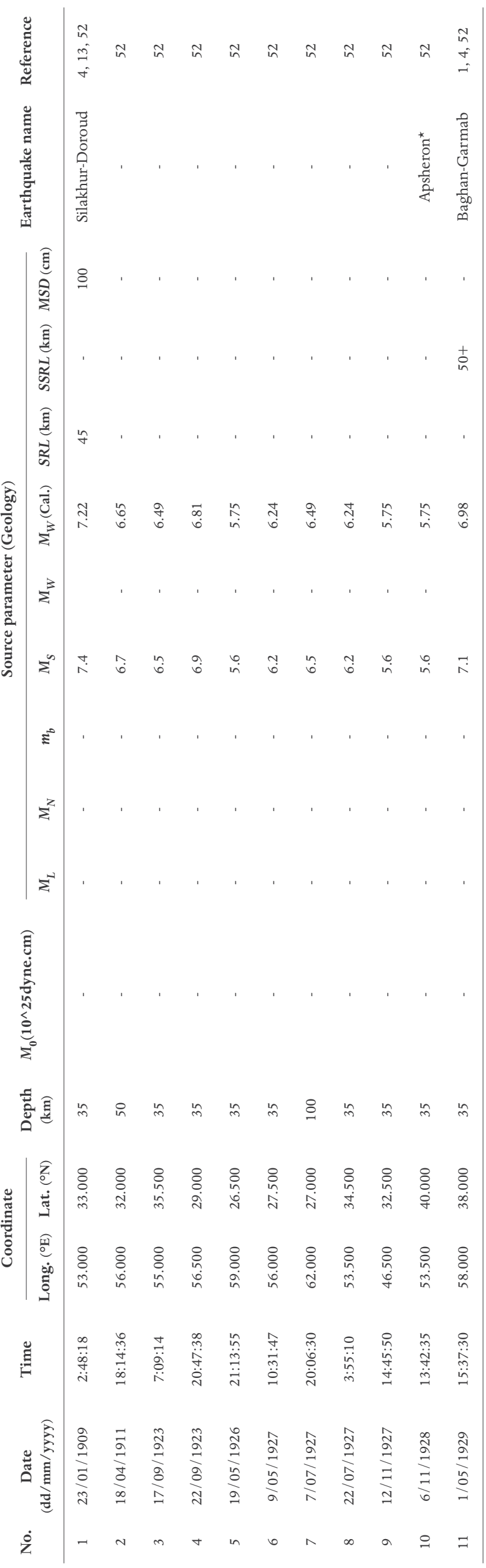




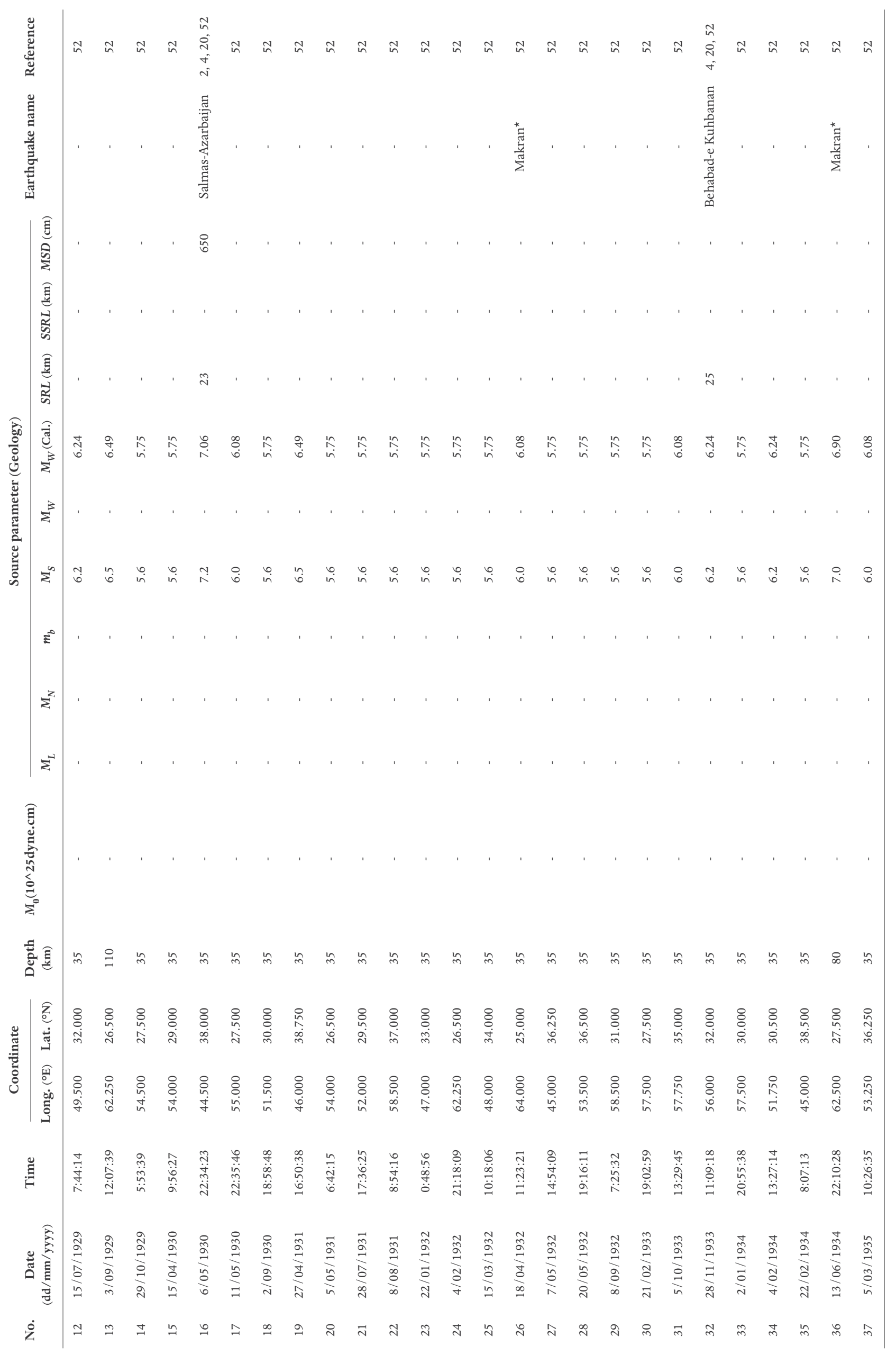




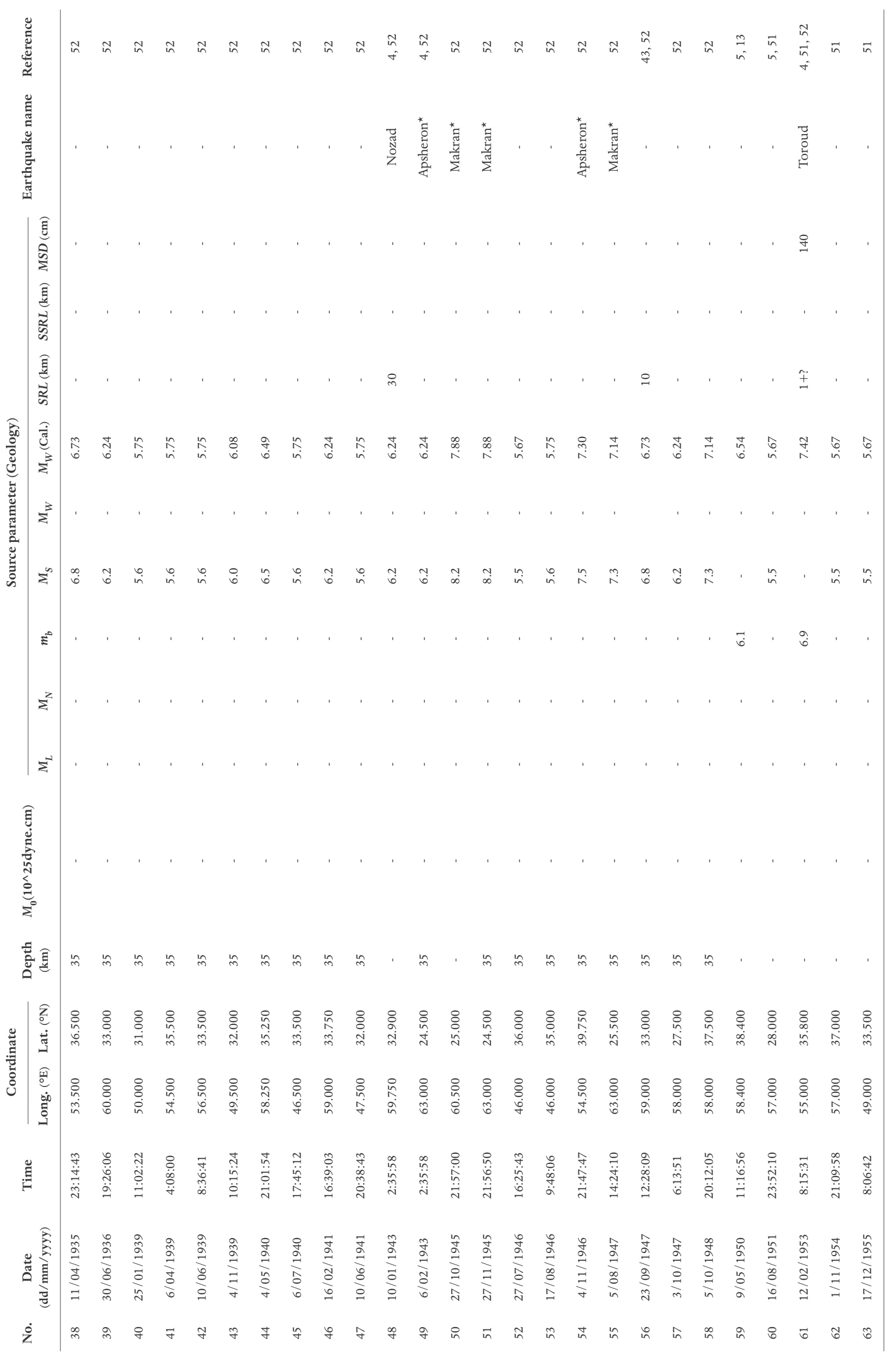


RELATIONS BETWEEN SOURCE PARAMETERS FOR LARGE PERSIAN EARTHQUAKES

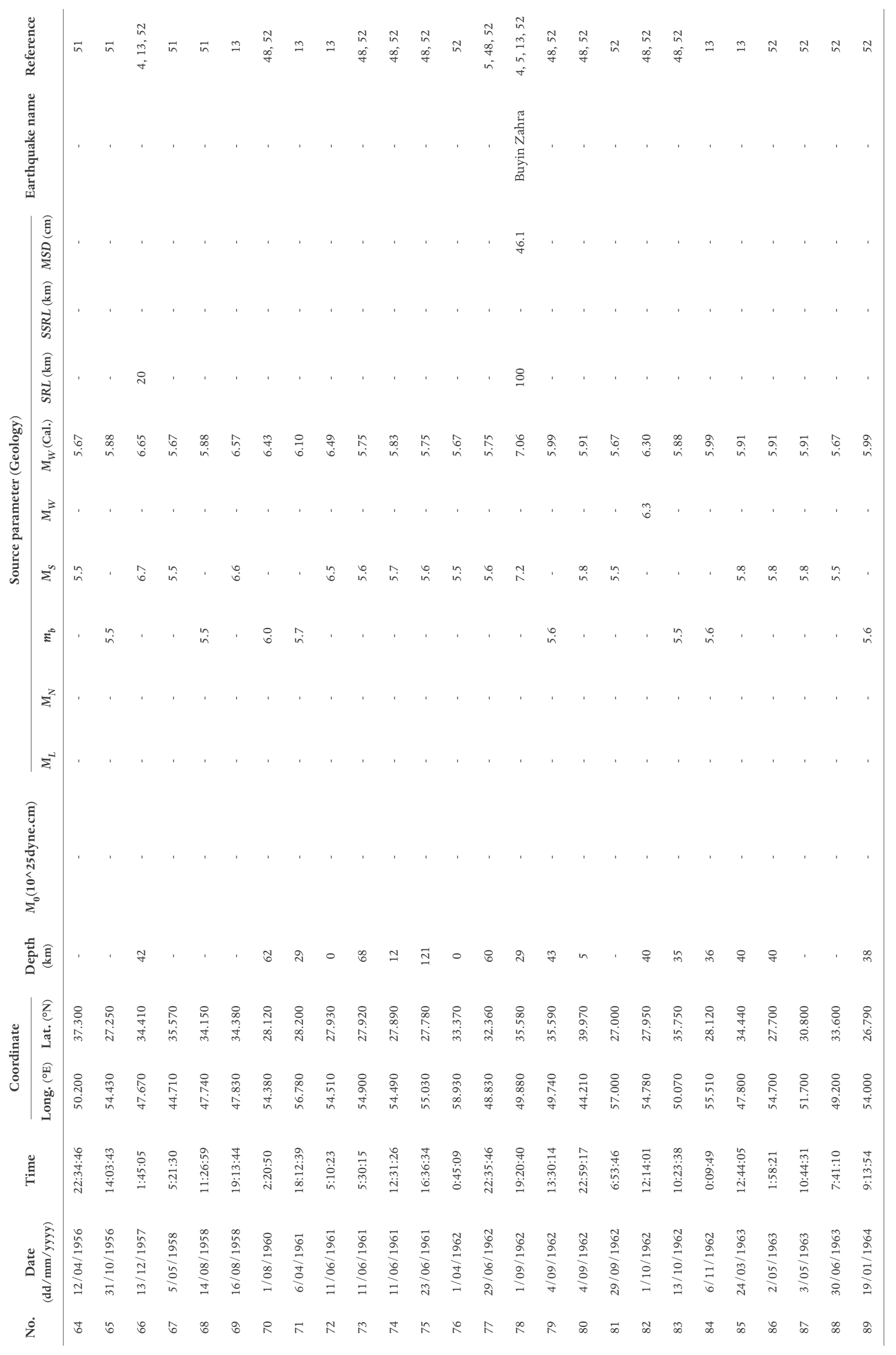




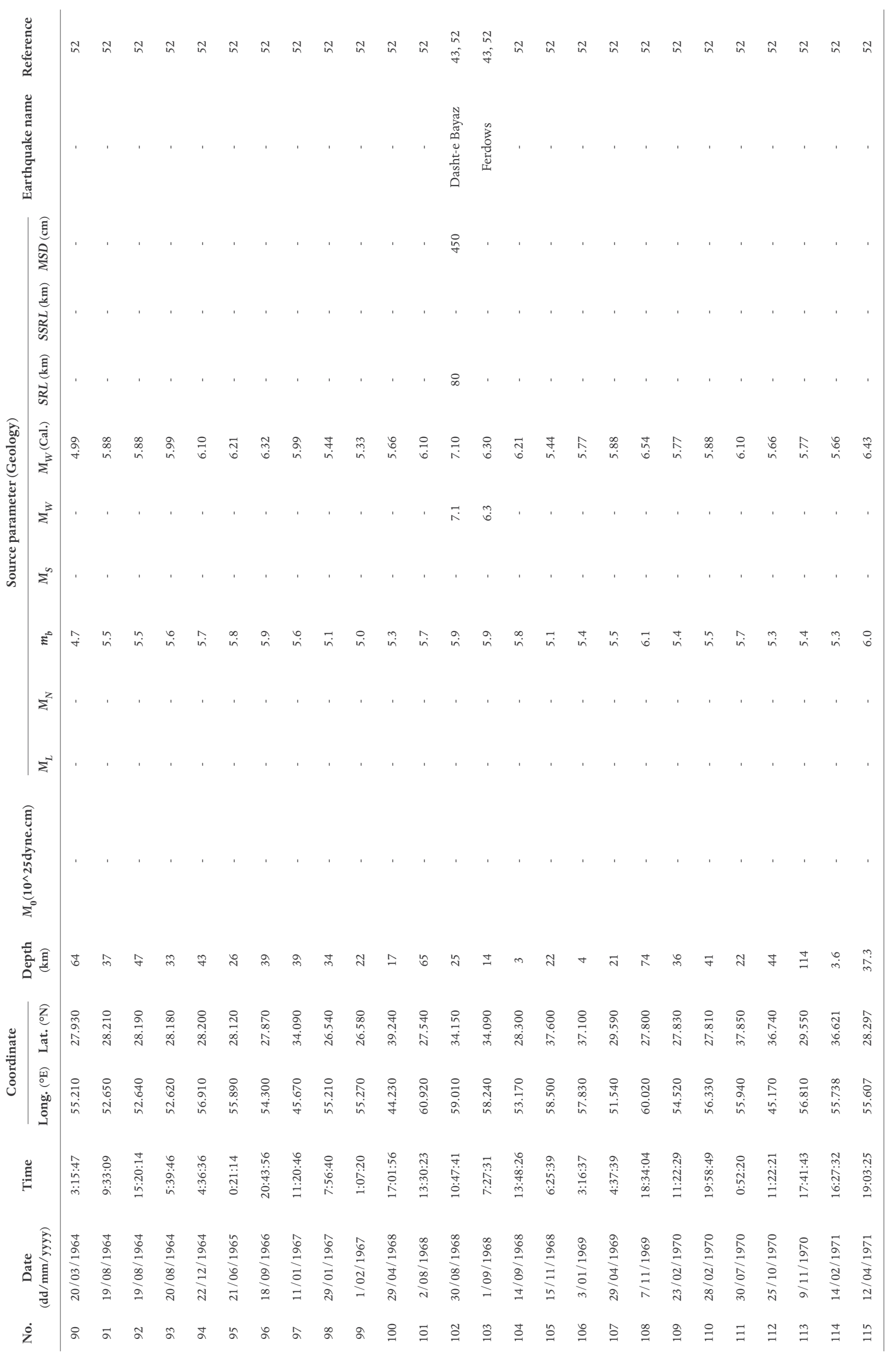




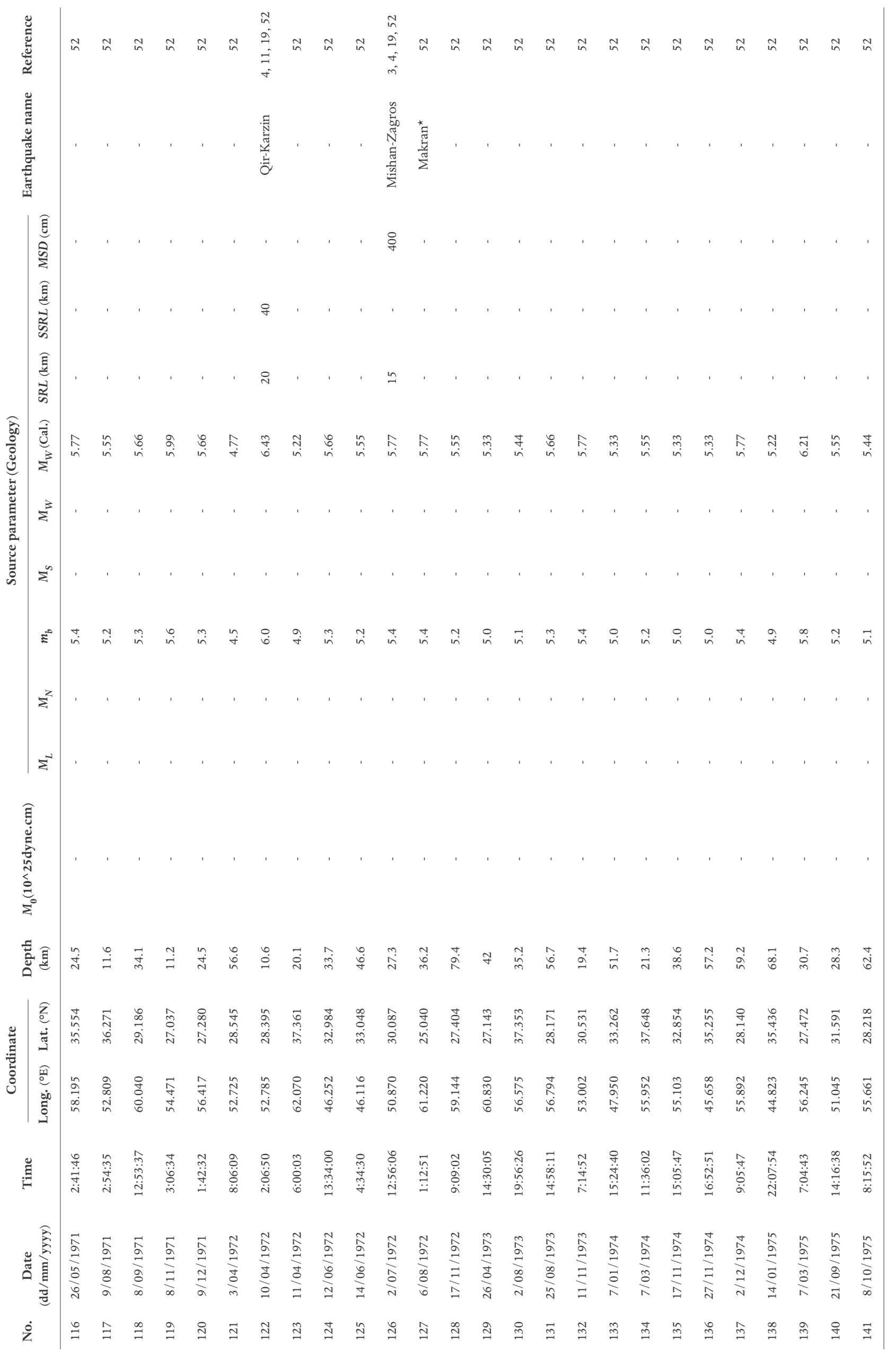




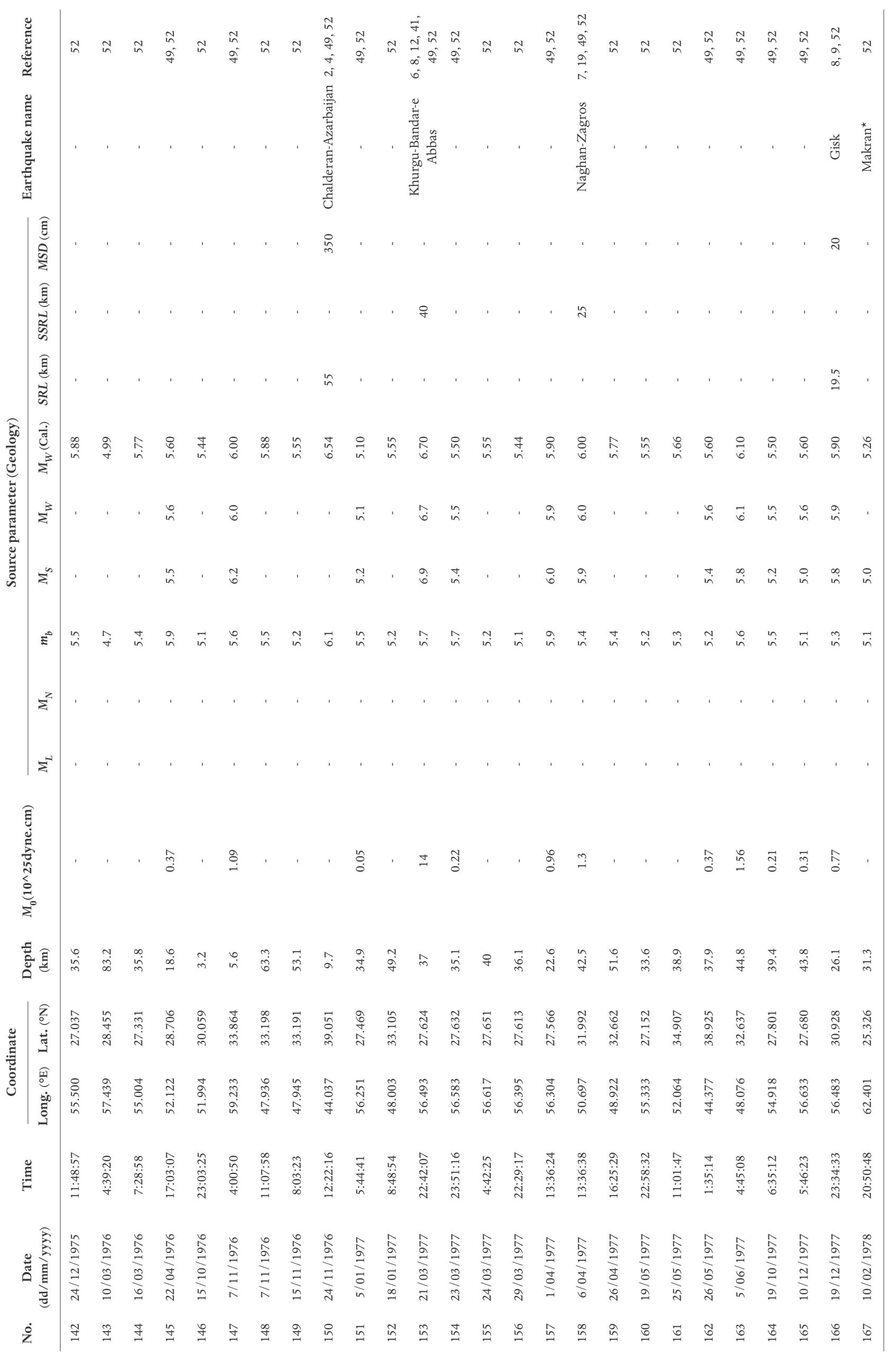




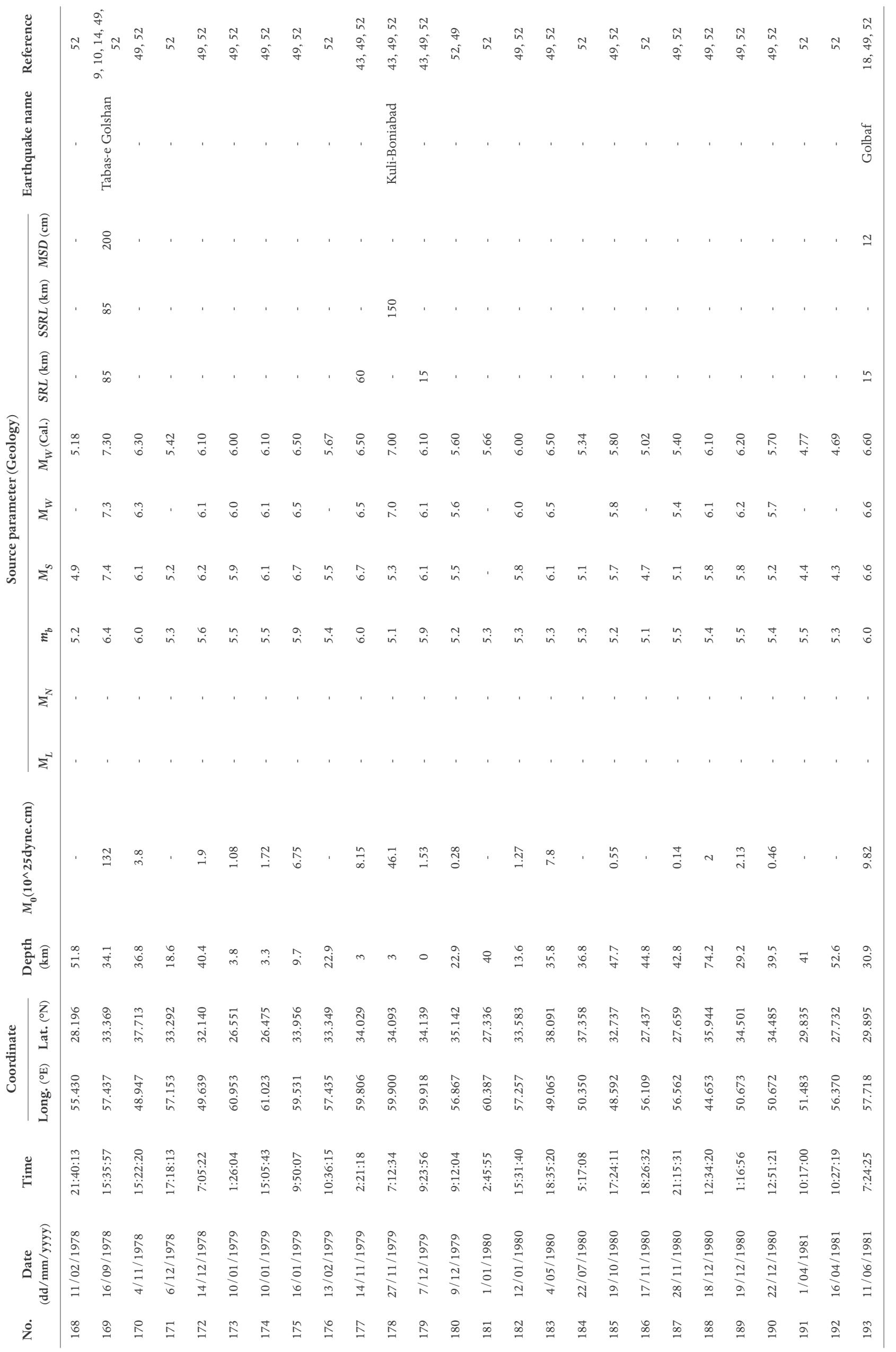




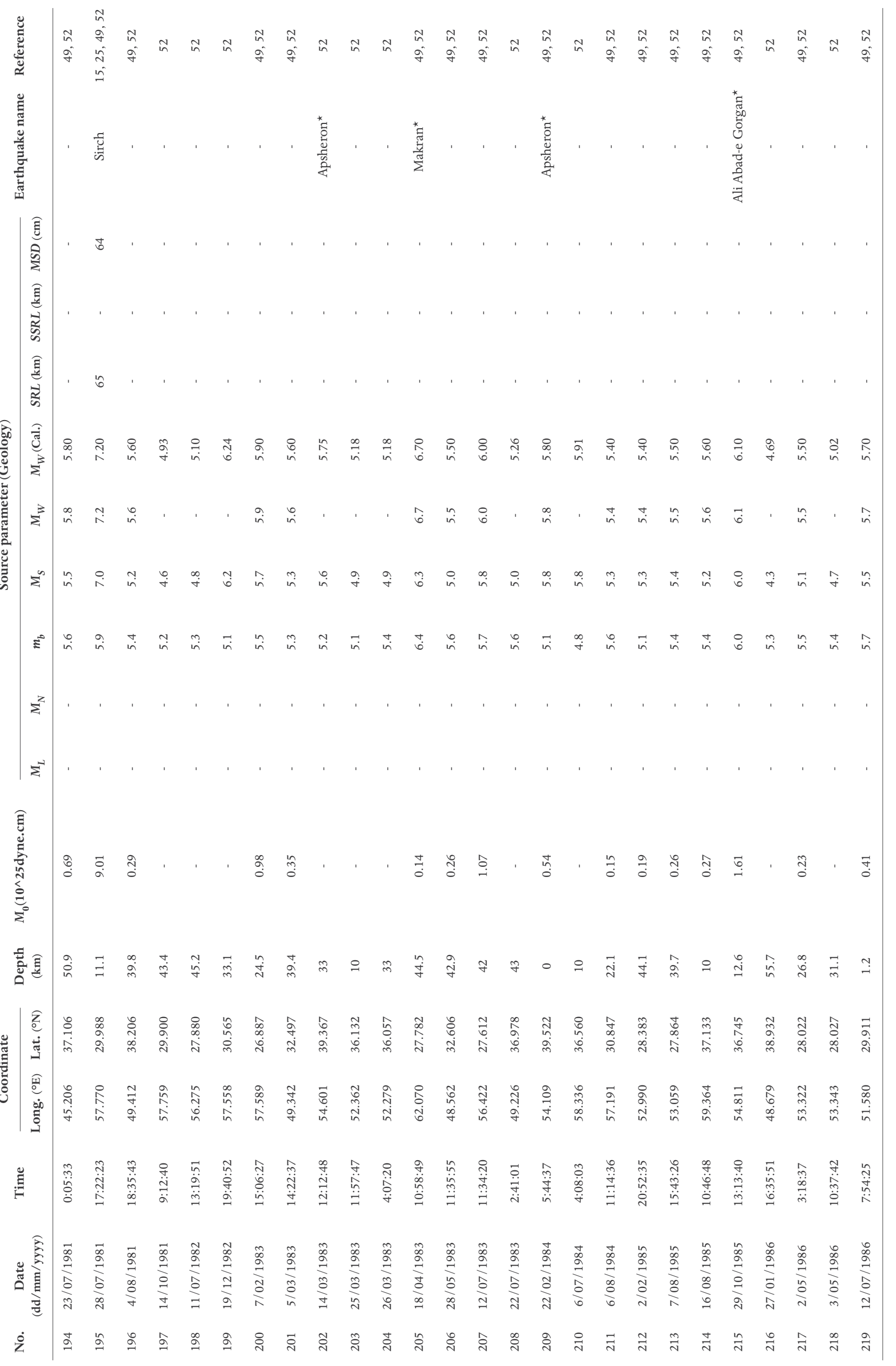




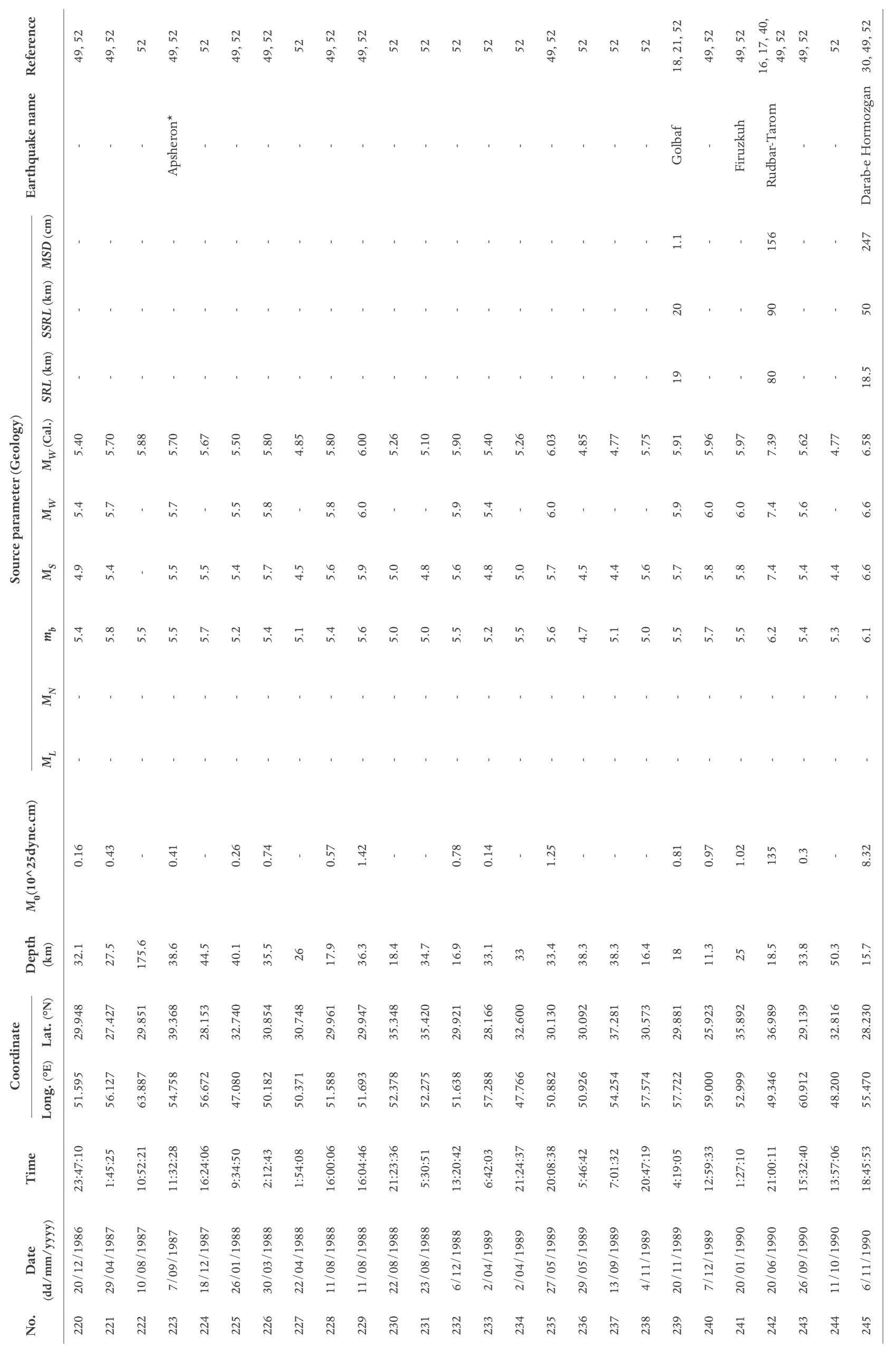




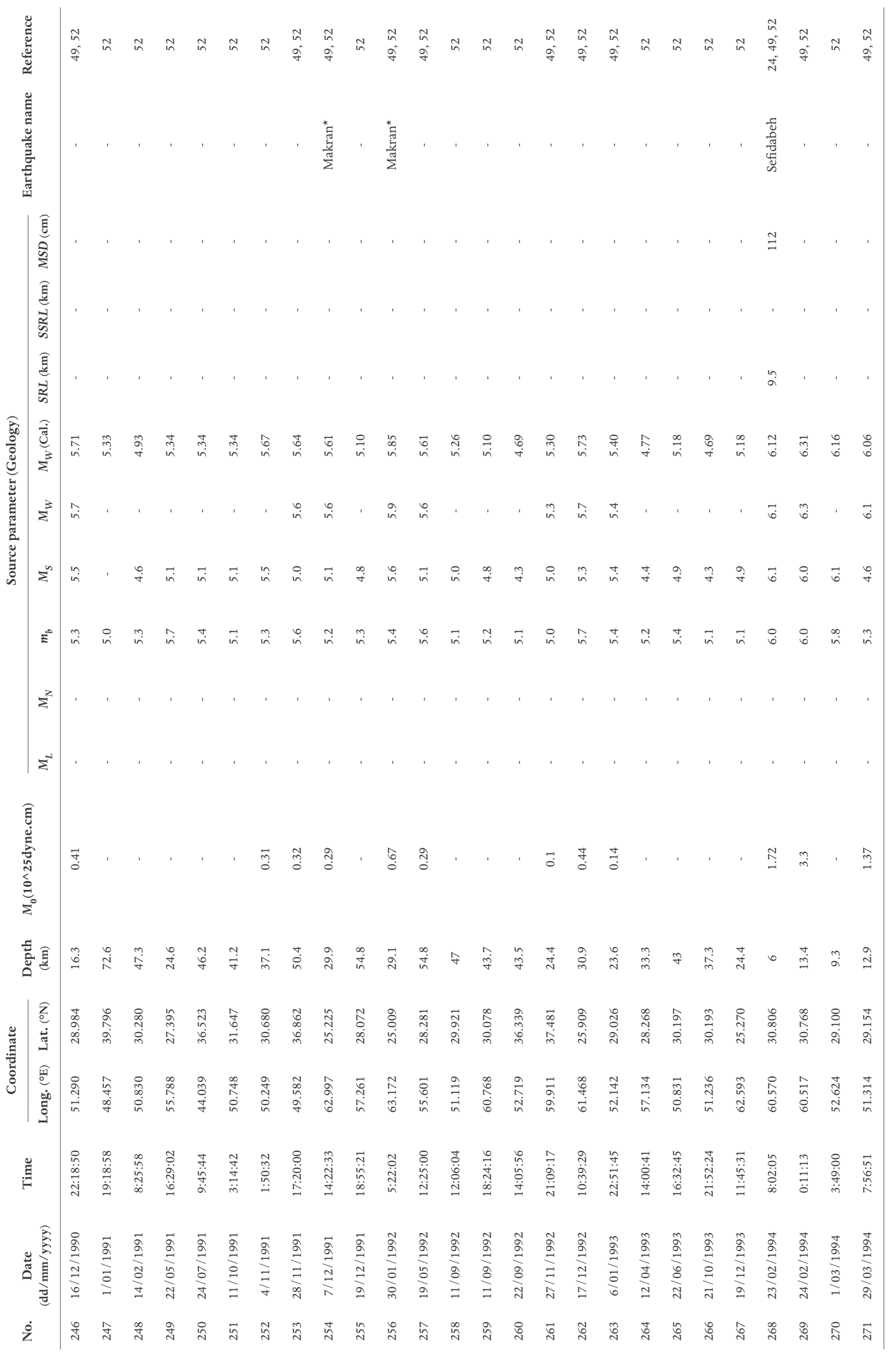




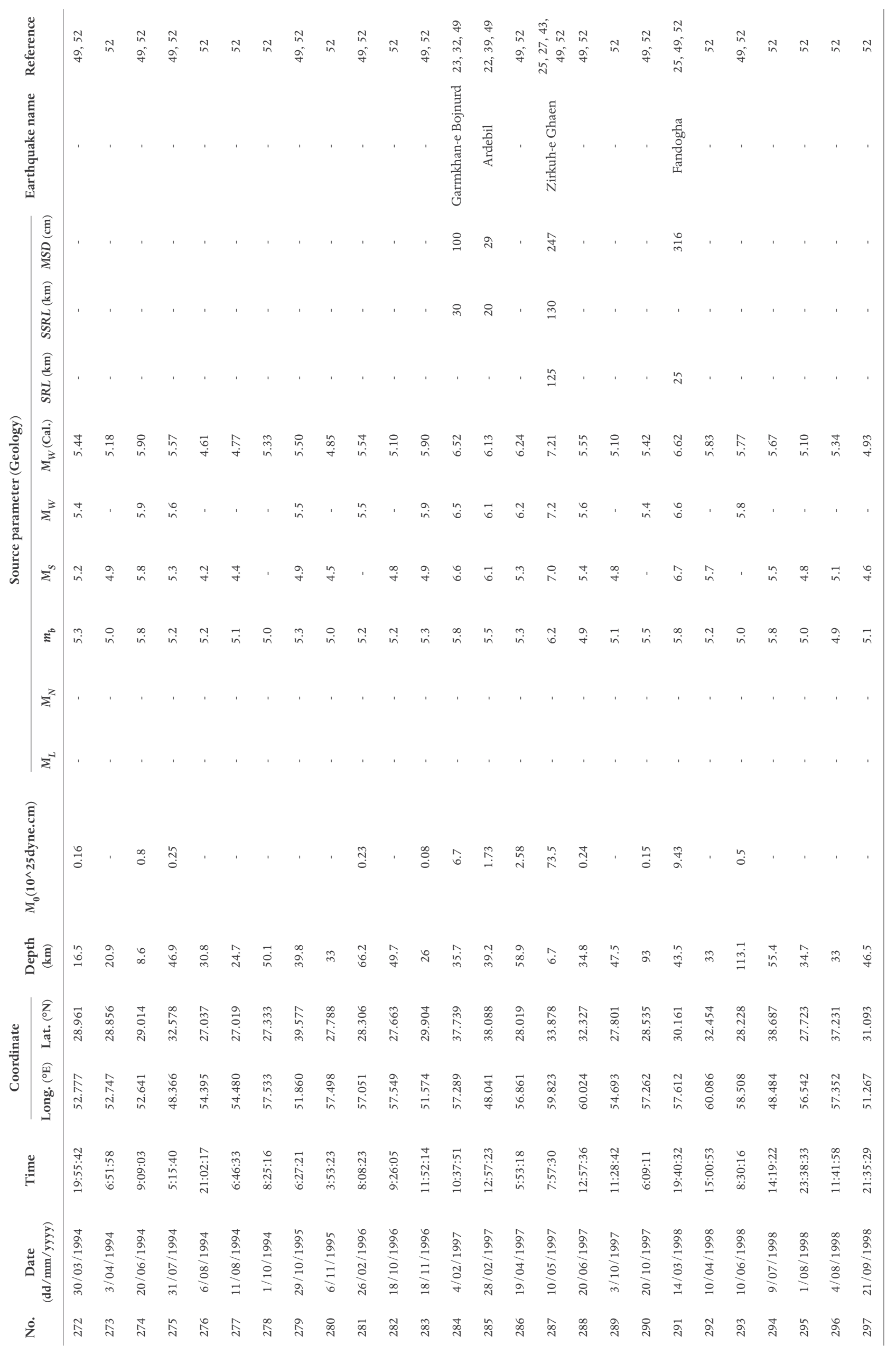




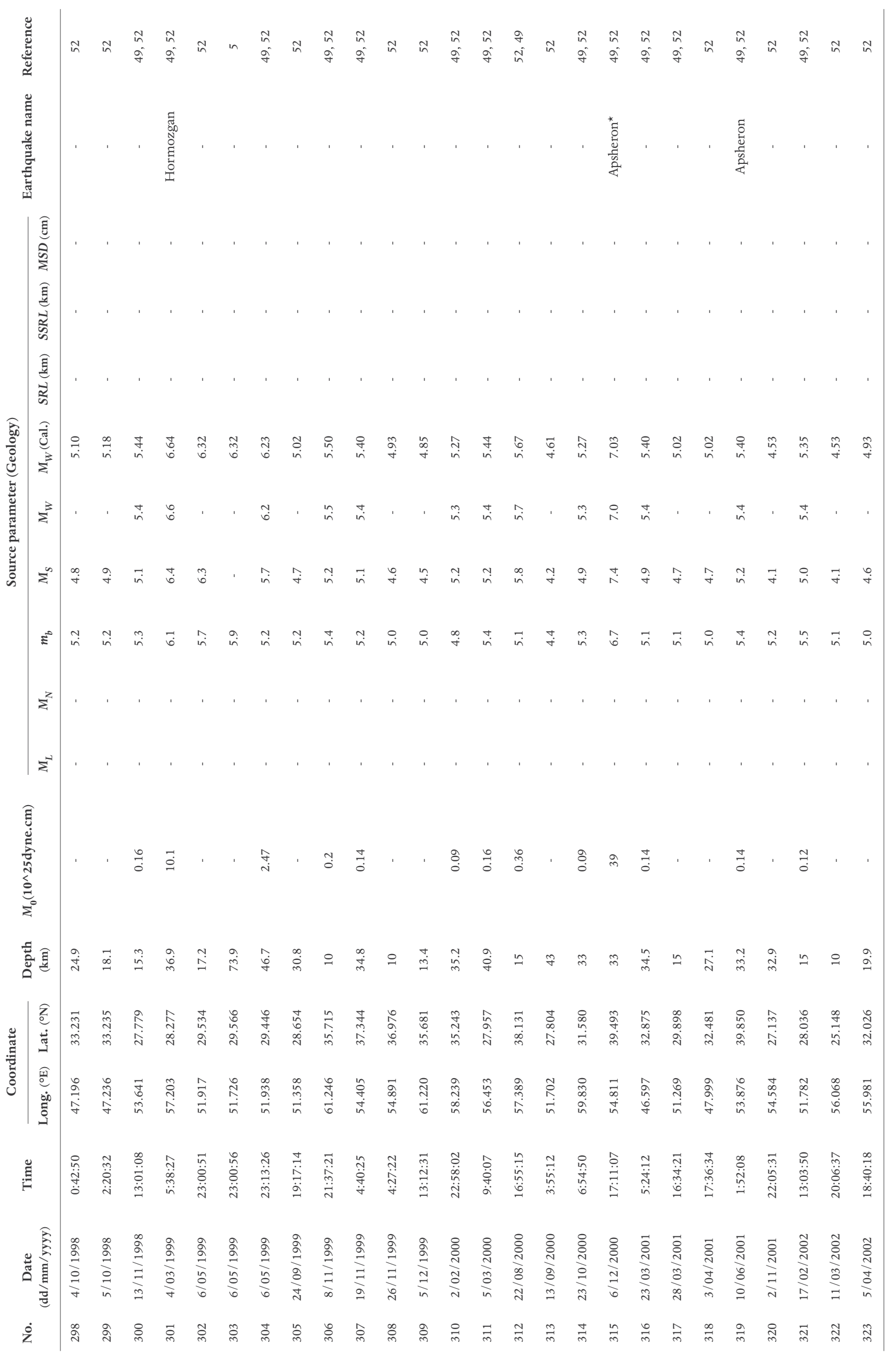




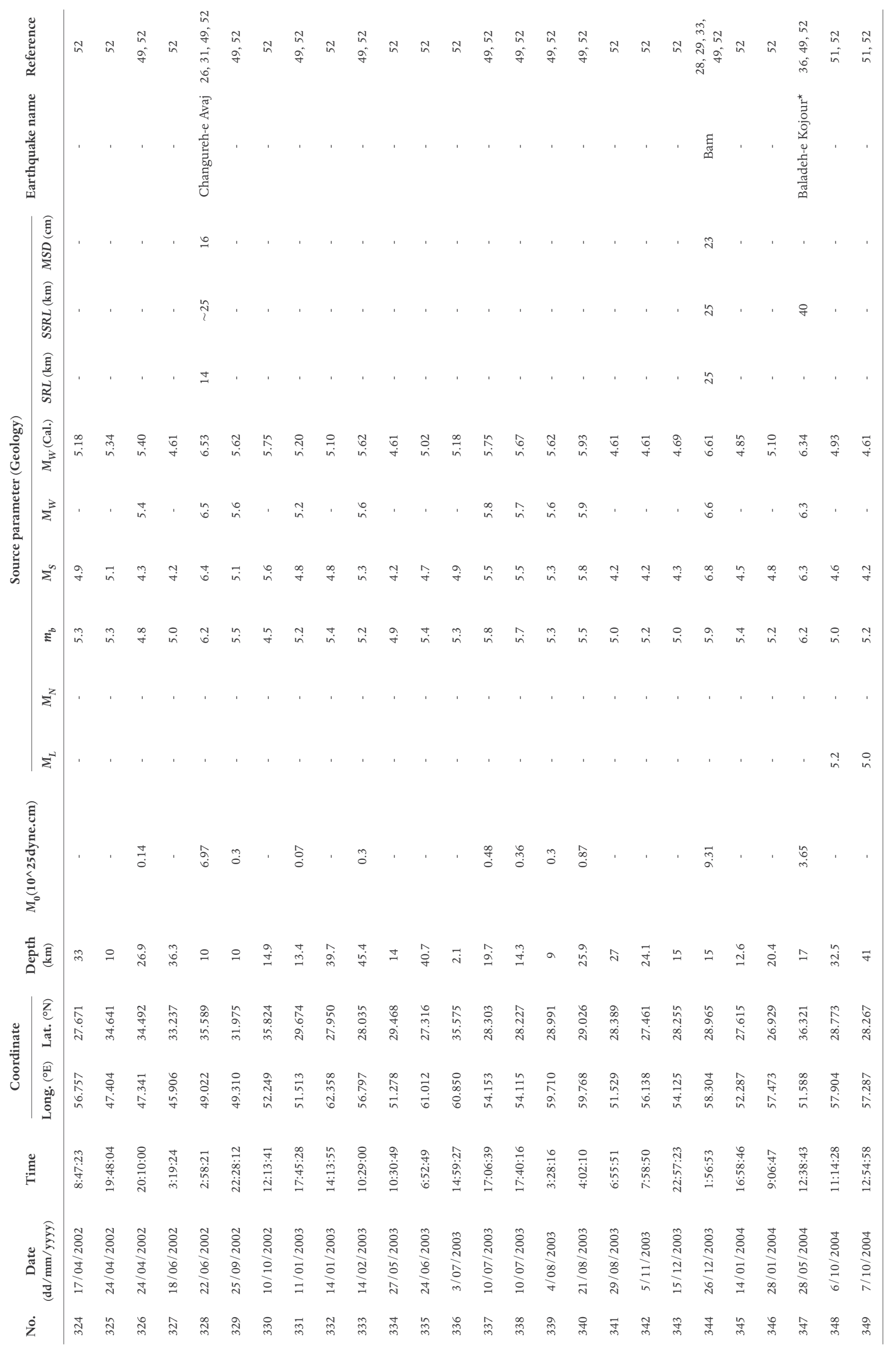




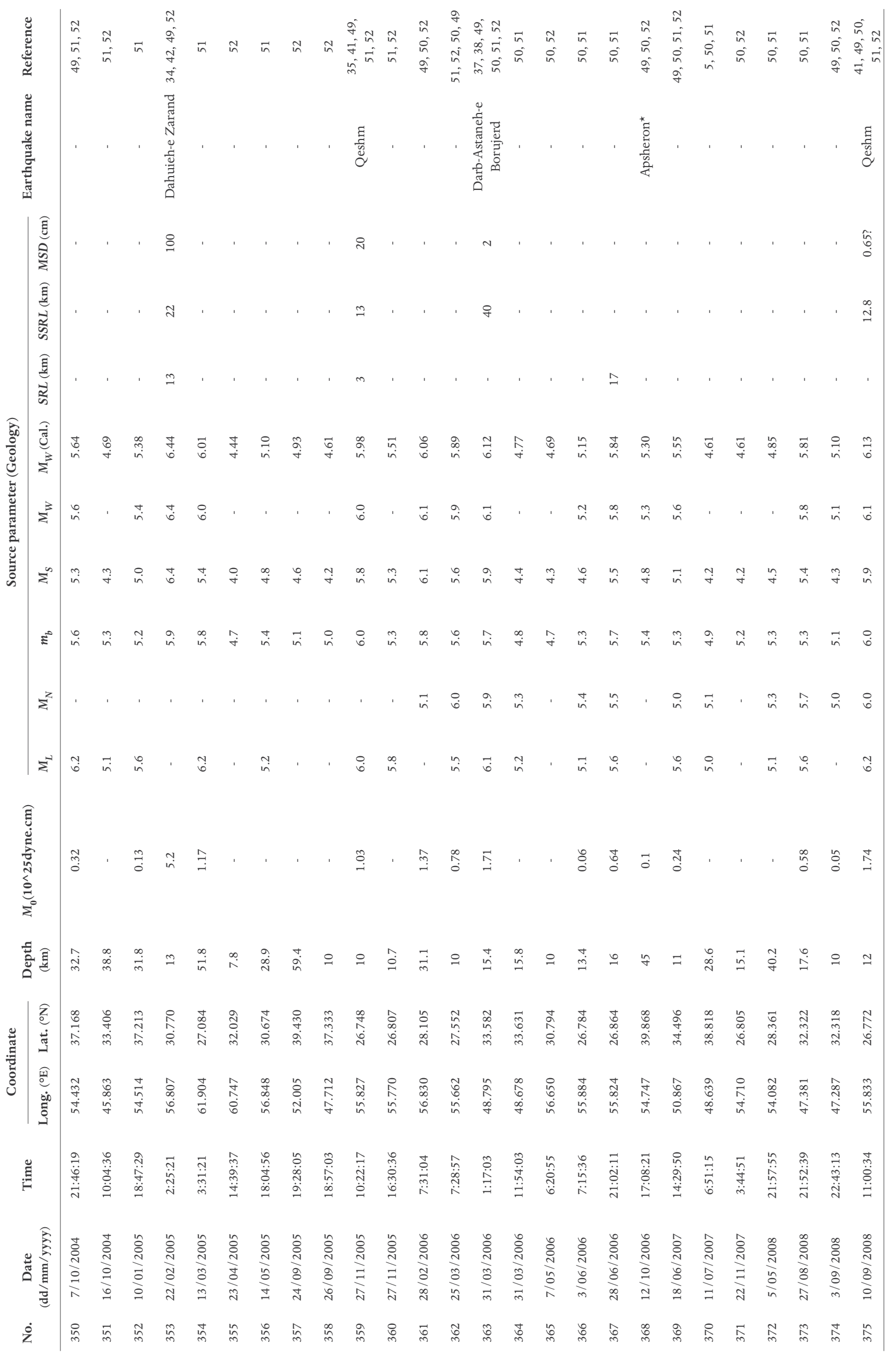




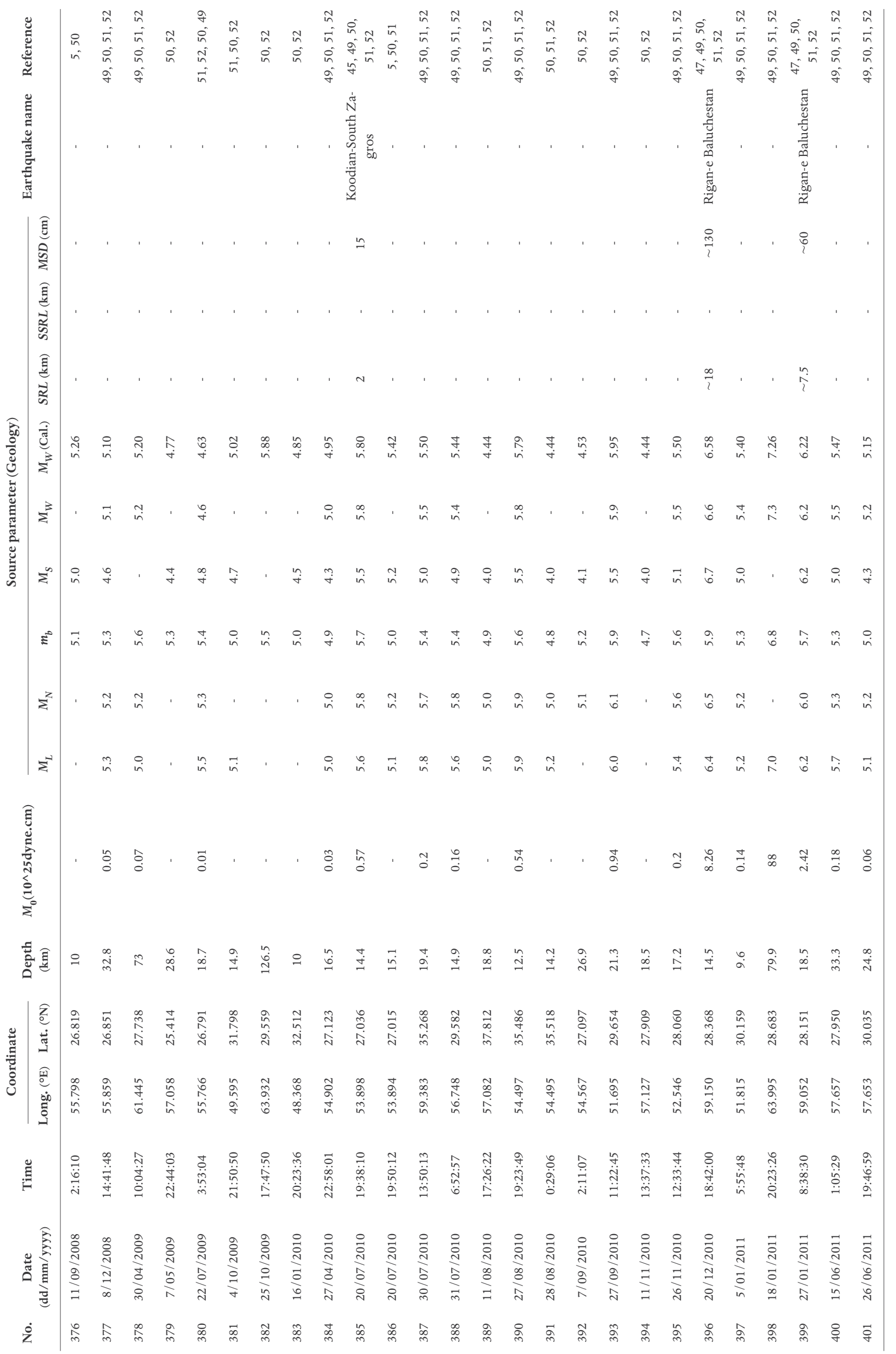




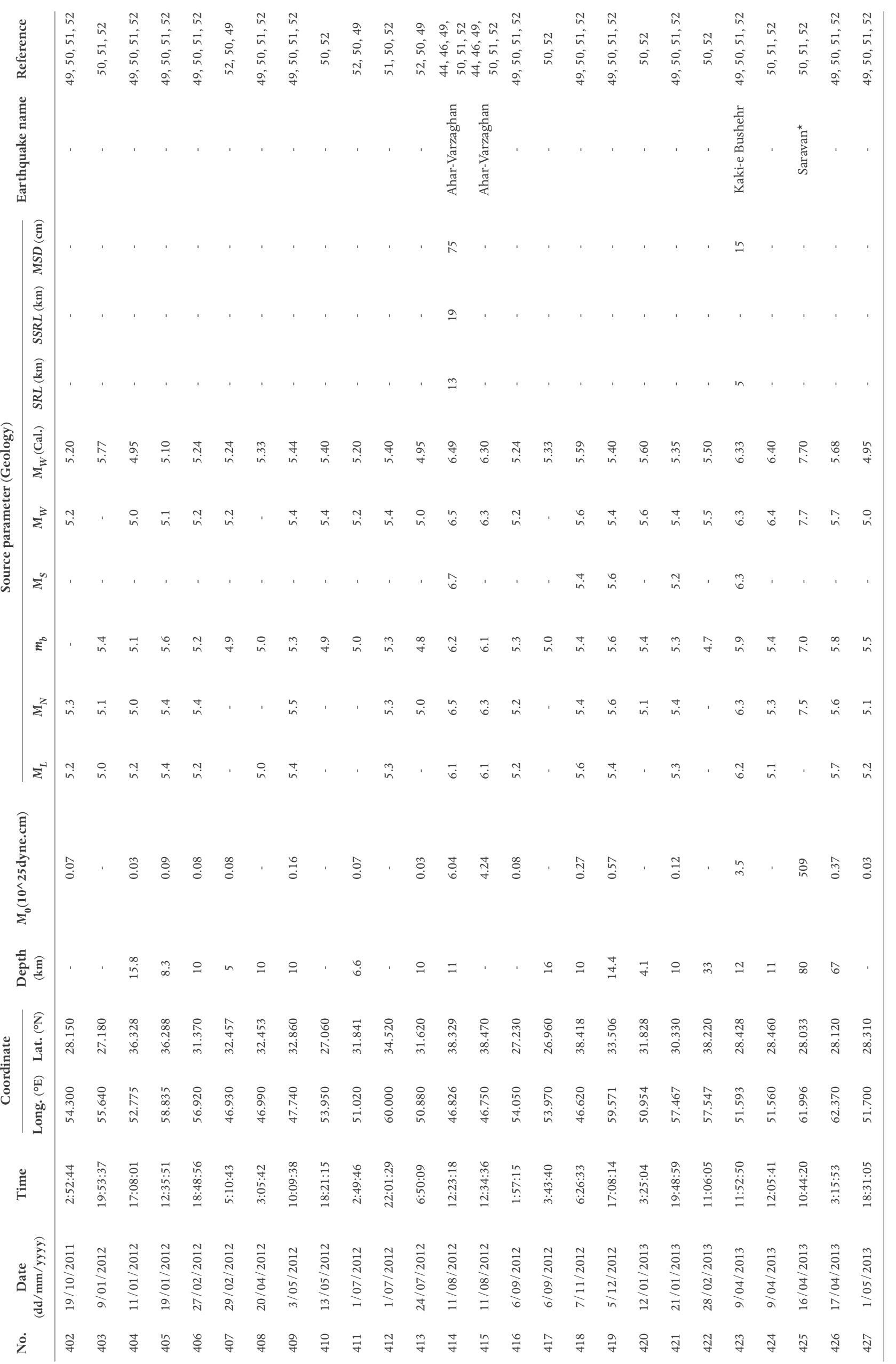




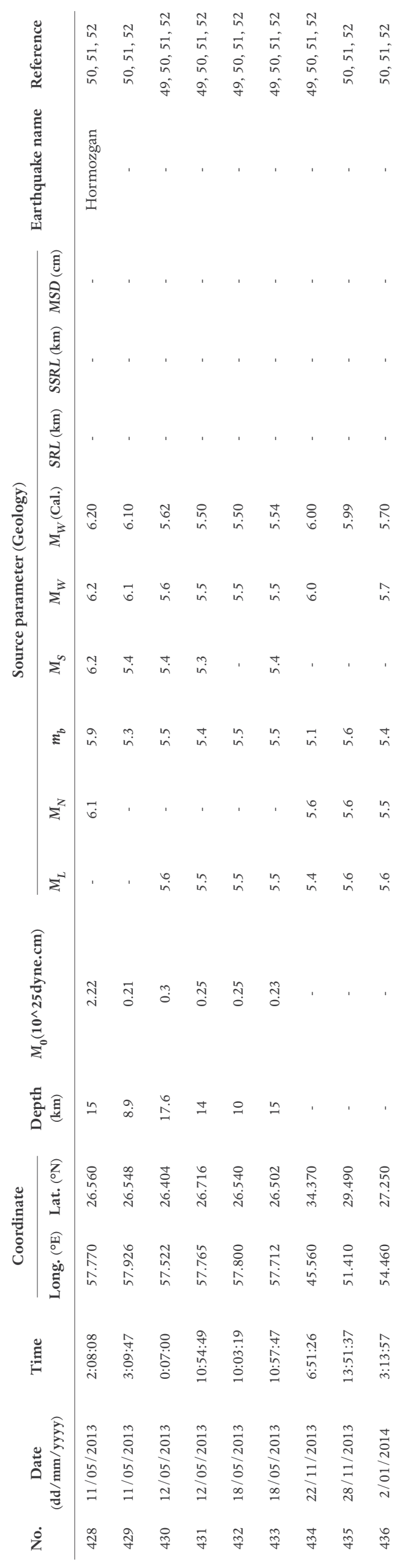

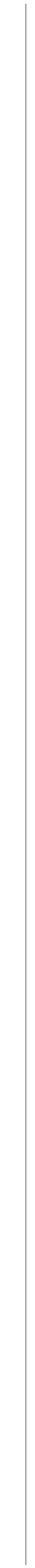

